\title{
INSULATING PROPERTIES OF SOLID DIELECTRICS
}

\author{
By Harvey L. Curtis
}

\section{CONTENTS}

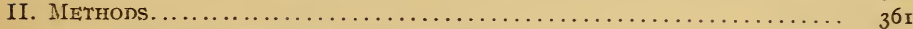

I. Methods of measuring the resistance..................... ${ }_{3}^{6}$ I

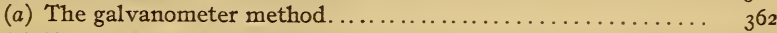

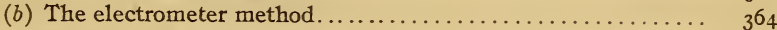

2. Methods of preparing the specimens.................... 366

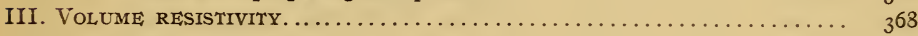

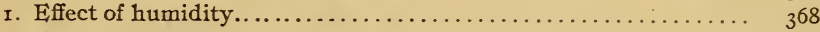

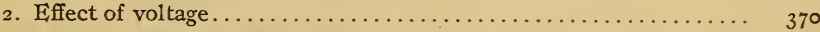

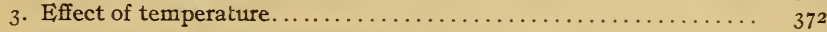

4. Effect of dielectric absorption........................ 373

5. Values of the volume resistivity $\ldots \ldots \ldots \ldots \ldots \ldots \ldots \ldots \ldots, 375$

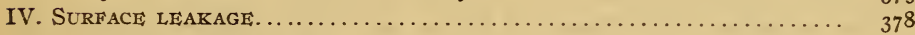

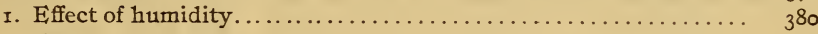

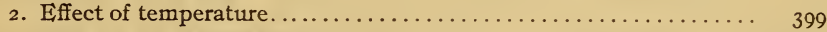

3. Effect of exposure to light........................ 400

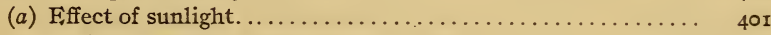

(I) Deterioration of hard rubber ............... $40 \mathrm{I}$

(2) Renovation of the surface of hard rubber........... 403

(3) Deterioration of other materials ................ 403

(b) Fffect of ultra-violet light....................... 404

4. Nature of surface leakage ........................ 409

5. Methods of computing surface resistivity $\ldots \ldots \ldots \ldots \ldots \ldots \ldots, 4 \ldots \ldots \ldots \ldots$

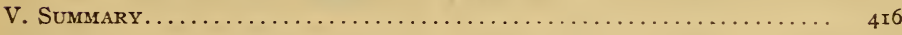

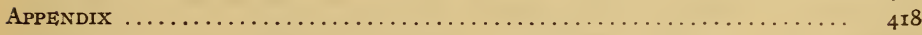

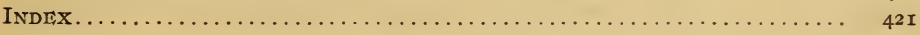

\section{INTRODUCTION}

For many years physicists, electrical engineers, and others using electrical apparatus have felt the need of some material to replace the hard rubber which is so extensively used where very high insulation is required. The reasons for this are its high cost, its mechanical limitations, and the fact that it deteriorates rapidly when exposed to light. Many insulating materials have made their appearance in recent years, yet there is very little data concerning them. This investigation was undertaken to determine the rate of deterioration of hard rubber and to make certain tests upon 
other materials to see if their electrical properties permit them to replace hard rubber, at least for certain uses. Incidentally, many substances were tested which can be considered as hard rubber substitutes only in special cases.

The suitability of an insulating material for any given purpose will depend upon its mechanical properties fully as much as upon its electrical properties. It is not, however, the purpose of this paper to discuss the mechanical properties ${ }^{1}$ of the materials considered.

There are several electrical properties of insulators between no two of which is there a known relationship. The most important of these are (I) the volume of resistivity of the material, (2) the leakage over the surface, (3) the dielectric absorption, (4) the dielectric strength, and (5) the dielectric constant. All of these properties are functions of the temperature, and some may also be affected by other physical conditions, such as applied voltage, humidity, pressure, etc.

The relative importance of these properties depends upon the use to which the material is to be put. In high tension installations a knowledge of the dielectric strength is of the greatest importance, but even here information concerning the other properties may be useful. However, in many cases the surface leakage will tell much more than the dielectric strength as to the suitability of a material for a given class of work. For instance, the important properties of a material to be used for insulating the terminals of resistance coils are its volume resistivity and surface leakage, the latter being usually the more important. Another similar case is the insulation of the terminals of condensers, especially those of small capacity.

Fortunately in low voltage work the commercial demands upon insulators do not require that they shall possess any one of the properties enumerated above in an unusual degree. Hence, in most cases there is a considerable number of insulators which, from an electrical point of view, will satisfy the requirements. The choice will then turn on the mechanical qualities and cost. However, cases frequently arise where one or more of the electrical qualities are the first consideration, and in such cases it is

\footnotetext{
${ }^{1}$ Both the electrical and mechanical properties of insulators are now being investigated by the " Kommission für Isolierstoffe," a preliminary report by Dr. H. Passavant appearing in the Elektrotech. Zs., 83 p. $450 ; 1912$.
} 
important to have reliable data available. A considerable amount of data concerning the dielectric constant and dielectric strength of insulating materials has been published, but even in this field much remains to be done. The absorption in dielectrics is only beginning to be carefully studied. The volume resistivity of dielectrics has been extensively studied, but it is often difficult to find reliable data upon materials in common use. The importance of surface leakage has long been appreciated, but it is only within a few years that careful measurements ${ }^{2}$ upon it have been made.

This paper presents results upon the volume resistivity and surface leakage of a number of insulating materials. The surface leakage was measured under varying conditions of temperature and humidity both before and after exposure to light. The volume resistivity was measured at different temperatures and the effect of absorbed moisture and of the magnitude and length of time of application of the voltage was studied. The aim has been to cover all the conditions that will normally be found in a physical laboratory.

\section{METHODS}

The methods employed may naturally be classed under two heads: (I) The methods of measuring the resistance; (2) Methods of preparing the specimen. Under the latter will fall the methods of maintaining the specimen under the desired conditions.

\section{METHODS OF MEASURING THE RESISTANCE.}

In measuring the resistance high accuracy was not required. An accuracy of Io per cent was considered sufficient. As a large number of samples were measured, and each sample measured several times, it was necessary to arrange the apparatus so that it could be worked rapidly. Measurements were made from $\mathrm{IO}^{4}$ ohms to $1 \mathrm{O}^{17}$ ohms, the upper limit being fixed by the sensibility of the apparatus.

It was found impossible to measure such an extreme range of resistance in a single set up. Hence, two different methods were employed: (a) The galvanometer method; $(b)$ the electrometer method.

\footnotetext{
2 The following are a few of the important references to this work: Mershon-High Voltage Measurements at Niagara, Trans. A. I. E. E., 27, p. 845; 1908. Dietrich-On the Conductivity of Electric Insulators, Diss. Göttingen, 1909, and Phys. Zs., 11, p. 187; 1910. Rebora-Experimental Researches on Insulators of Glass and Porcelain, Atti dell 'Associazione Elettrotrechnica Ita1., 14, p. 665; rg ro. Passevant-L.oc. cit. Schroedinger-On the Conductivity of Electricity Over the Surface of Insulators in Humid Air. Acad. Wiss. Wien, Sitz. Ber., 119, 2a, p. I215; rgre.
} 
(a) THE GALVANOMETER METHOD

The diagram of Fig. I shows the galvanometer method as arranged for measuring the volume resistivity of the specimen. The terminal $\mathrm{F}$ of the battery is connected to the mercury on which the specimen floats. The current flows through the specimen to the mercury contained in an open cylinder of known area which is connected to $\mathrm{D}$. The megohm in series serves to protect the galvanometer and is usually negligible relative to the resistance of the specimen. To prevent the current which flows over the surface of the specimen from reaching $D$, a guard ring of mercury surrounds the inner cylinder, but is insulated from it. This guard ring is connected directly to the opposite terminal of the battery. In measuring a surface resistance or any resistance in which a guard ring is unnecessary the unknown resistance is connected directly between $\mathrm{D}$ and $\mathrm{F}$.

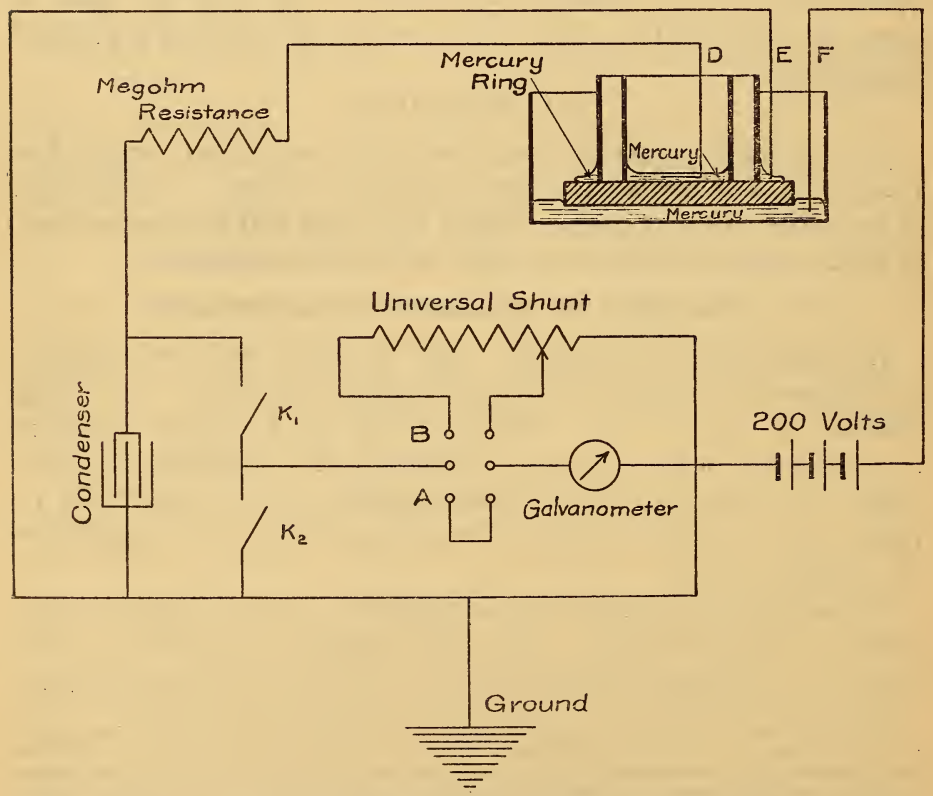

FrG. I.-Connections for measuring volume resistivity by the galvanometer method 
For supplying the voltage, trays of small storage cells are used. This battery and the other apparatus are placed on metal plates which are grounded. One terminal of the battery is also connected to the same ground. The key $\mathrm{K}_{2}$ is for short circuiting the galvanometer, while the key $\mathrm{K}_{1}$ closes the circuit through the galvanometer. When the double throw switch is in the direction $\mathrm{B}$, the galvanometer is connected in parallel with a universal shunt. This can readily be adjusted so that I, I/IO, I/IOO, I/IO0O, or I/I0000 of the total current passes through the galvanometer. The Sullivan galvanometer had a current sensitiveness of 2000 $\mathrm{mm}$ per microampere, with a scale distance of 2 meters. Using a battery of 200 volts, as was done in almost all cases, resistances from $1 \mathrm{O}^{4}$ to $\mathrm{II}^{11}$ ohms can be measured to an accuracy of $\mathrm{Io}$ per cent. When the double-throw switch is thrown to A, the galvanometer is connected directly in series with the specimen without the damping resistance which is contained in the universal shunt. If the current is so small that it does not produce an appreciable deflection upon closing the key $\mathrm{K}_{1}$, the key is opened so that the current flowing through the specimen will charge the condenser. At the end of a time $t$, the key $\mathrm{K}_{1}$ is again closed and the charge which has accumulated is discharged through the galvanometer. From the ballistic constant of the galvanometer, the resistance of the specimen can be computed in the following manner.

If $Q$ is the quantity of electricity upon the condenser of capacity $C$ at a time $t$ after opening $\mathrm{K}_{1}$, $i$ the current flowing through the specimen and $R$ its resistance, then since $Q=\int_{0}^{t} i d t$

$$
E=R i+\frac{\mathrm{I}}{C} \int_{0}^{t} i d t
$$

The solution of this integral equation gives $i=\frac{E}{R} e^{\frac{-t}{R C}}$

and hence $Q=E C\left(I-e^{\frac{-t}{R C}}\right)$

Expanding the exponential

$$
Q=\frac{E t}{R}\left(I-\frac{t}{2 R C}+\frac{t^{2}}{6 R^{2} C^{2}}-\ldots\right)
$$

Hence, if $t / 2 R C$ is small relative to unity,

$$
R=\frac{E t}{Q}=\frac{E t}{K d}
$$


where $K$ is the ballistic constant of the galvanometer and $d$ the deflection. This method of computing does not introduce an error of more than I or 2 per cent, which for our purpose is sufficiently accurate.

The condenser should have negligible leakage and absorption. This was secured by placing an air condenser, insulated by glass pillars, in a chamber dried with phosphorus pentoxide. The Sullivan galvanometer had a ballastic sensitiveness of $1400 \mathrm{~mm}$ per microcoulomb with a scale distance of 2 meters. By this method resistances from $1 \mathrm{O}^{11}$ to $1 \mathrm{O}^{15} \mathrm{ohms}$ can be measured. It would appear that there should be no limit to the resistances that can be measured provided the time of leakage is sufficiently long. However, in practice it was found impracticable to use a time longer than five minutes, so that a resistance of more than ${ }^{15}$ ohms could not be measured by this method.

\section{(b) THE ELECTROMETER METHOD}

For measuring resistances higher than ${ }^{10}{ }^{15}$ ohms a Dolezalek quadrant electrometer having a capacity of $\mathrm{I} 30 \mu \mu \mathrm{f}$. was employed. By means of it resistances as high as $10^{17} \mathrm{ohms}$ could be measured. The diagram of Fig. 2 shows the connections for measuring the surface resistivity. The lead to one pair of quadrants is entirely surrounded by an earthed shield, while the other pair of quadrants is connected to earth. The surface leakage is over the surface between the inner and outer cylinders which rest on the insulator.

To measure the volume resistivity of the specimen, the battery $B$ is disconnected from the outer ring and connected to the mercury in which the specimen is floated (see Fig. I). The outer ring is then connected to earth. The current which flows onto the inner quadrant must now flow through the specimen.

If the needle of the electrometer is maintained at a constant potential, the deflection of the needle will depend on the quantity of electricity on the inner quadrant. If the external electromotive force $E$ is high relative to the counter electromotive force due to the charge on the quadrants, then the current through the insulator may be considered constant. In this case $R=\frac{E}{I}=\frac{E t}{Q}=\frac{E t}{K d}$, where 
$E$ is the applied electromotive force, $t$ the time necessary to produce a deflection $d$, and $K$ is the quantity of electricity necessary to produce unit deflection. This is similar to the method using a ballistic galvanometer, but differs in that the quantity can be determined at any instant.

To determine the constant of the instrument, a sample whose resistance could be measured by both the galvanometer and electrometer methods was employed. To obtain a check upon this, two

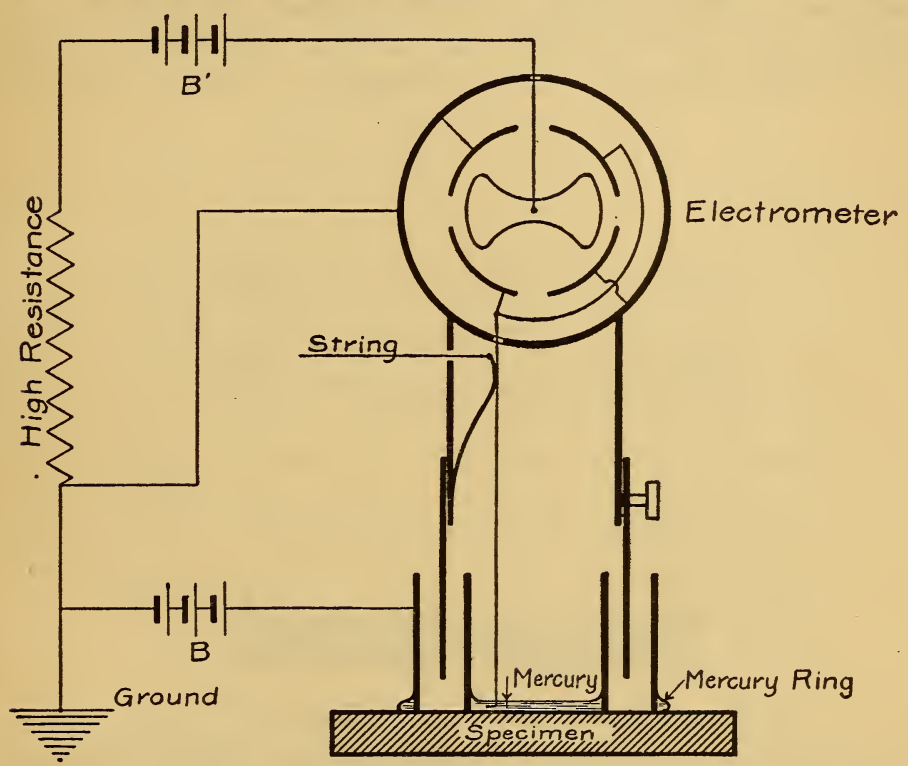

FIG. 2.-Connections for measuring surface resistivity by the electrometer method

other samples were chosen having resistance higher and lower, respectively, than the one indicated above. The lower resistance was measured first with the galvanometer method, and then with the electrometer method using a shunt of several thousandths of a microfarad to reduce the sensitivity of the electrometer. The sample of higher resistance was then measured using the electrometer both shunted and unshunted. The two methods of ob- 
taining the constant $K$ gave concordant results, the value being $6 \times 10^{-10}$ coulombs for a deflection of a $\mathrm{cm}$. at a scale distance of I. 3 meters with roo volts on the needle.

\section{METHODS OF PREPARING THE SPECIMEN}

For measuring the surface leakage, the material was obtained, whenever possible, in plates $10 \mathrm{~cm}$ square by $\mathrm{I} \mathrm{cm}$ thick. Metal strips I cm wide were clamped to this with their adjacent edges I $\mathrm{cm}$ apart, as shown in Fig. 3. The resistance was measured between strips A and strips B. The surface resistivity is assumed to be twenty times the resistance measured. (Surface resistivity

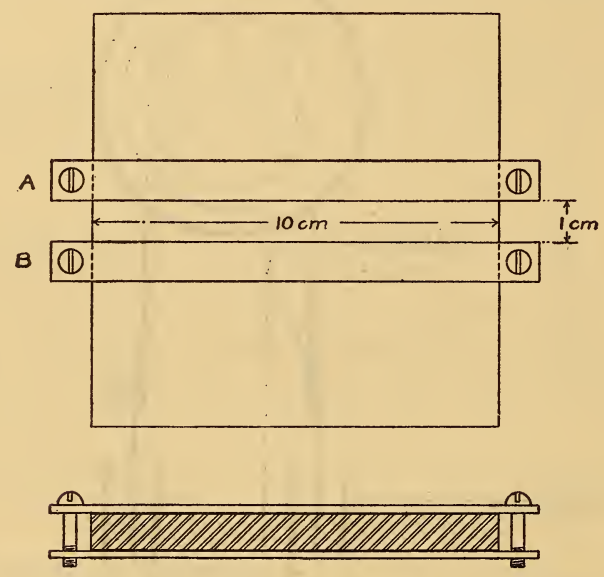

FIG. 3.-Specimen arranged to measure surface resistivity

is defined in Sec. IV below.) While this is not strictly true, since there is leakage over the edges as well as over the face of the specimen, yet the correction is too small to take account of in the present work. To insure good contact, tinfoil was wrapped around the metal strips and carefully pressed against the surface of the insulator along the inside edge of each strip.

In some cases tubes of the material were used. In such cases wires were tightly twisted around the tube at a distance of $\mathrm{I}$ $\mathrm{cm}$ apart and the resistance between these wires measured.

For determining the effect of temperature and humidity it was necessary to place the samples in a case, the temperature and 
humidity of which could be maintained constant. The temperature was maintained constant by a vapor pressure thermostat. The humidity was regulated by placing in the case an open vessel containing a sulphuric acid solution of the proper strength to give the desired humidity. The curve of Fig. 4 was constructed from Regnault's data, and from it the correct strength of acid could readily be determined. For very low humidities phosphorous pentoxide was used in the place of sulphuric acid. It was found necessary to keep out of the case all large blocks of wood and other absorbing materials. The air was thoroughly stirred by an 8 -inch

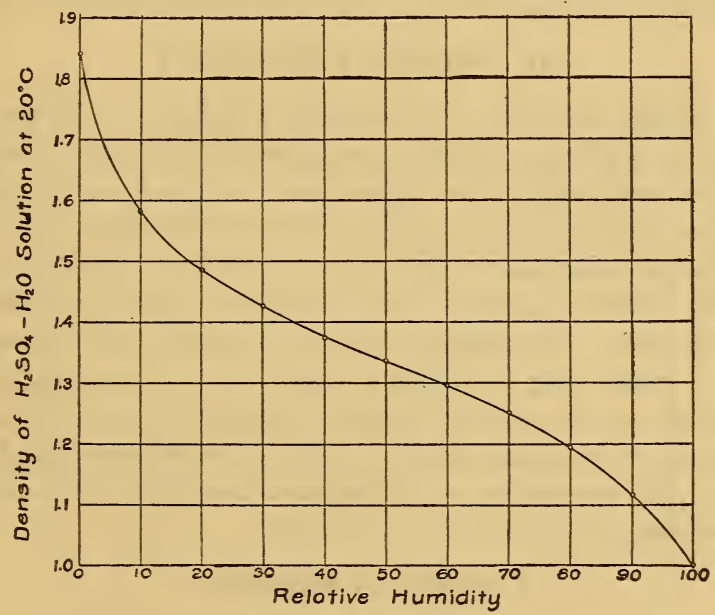

FIG. 4.-Curve showing the relationship between the density of a sulphuric acid solution and the relative humidity which will be maintained by it in an inclosure

fan, the driving motor being outside of the case. The leads to the specimens were brought out through blocks of paraffin on the top of the case. These were melted together, so that the case was sealed almost air-tight. A glass window permitted the reading of the temperature and humidity.

The humidity was measured by determining the temperature at which dew would form on a polished metal surface. The deposit of dew was usually obtained by circulating cold water through a metal tube, but for very low humidities it was found necessary 
to use alcohol in the tube and cool it by adding carbon dioxide snow.

For measuring the volume resistivity, the material was floated on mercury and an amalgamated copper block surrounded by a guard ring placed on the upper side. It was hoped in this way to reduce contact and surface leakage errors to a mimimum, but in some cases such errors were found to exist. Therefore, in the later work the copper block was replaced by a copper tube in which, after placing it upon the specimen, sufficient mercury was poured to cover the bottom. A ring of mercury was also made around the outside of the guard ring, so that all contacts were of mercury.

\section{VOLUME RESISTIVITY}

The volume resistivity of a material is defined as the resistance to the current flowing through the material between two opposite faces of a centimeter cube. The direct measurement consists in measuring the resistance between two opposite faces of a slab of the material, using electrodes of known area. To insure that the electrodes were in contact with the material, mercury electrodes were employed. To eliminate surface leakage from the measurements, a guard ring of mercury was used. The arrangement is seen in Fig. I. As a check upon the results, two sets of electrodes whose areas were in the ratio of 3 to $I$ were generally used. The values of the resistivity as determined from these two areas did not often vary by more than io per cent.

\section{EFFECT OF HUMIDITY ${ }^{3}$}

In certain cases results taken at different times did not agree satisfactorily. In seeking a cause for this, the question naturally arose as to whether the humidity of the air in which the sample had been kept before being measured could affect the volume resistivity. In order to test this, samples which had been maintained for some time in air of one humidity were surrounded by air of another humidity and maintained in this condition for several weeks. The volume resistivity was measured at frequent intervals during this time.

${ }^{3}$ Evershed (J. I. E. E., 52, p. 51; 1914) has published an elaborate investigation on the effect of moisture on volume resistivity, using very porous materials such as paper and cloth. 
The results show that, in certain cases, the volume resistivity decreases with increasing humidity but that an equilibrium is reached only after a very long time. To illustrate this, several curves obtained from one series of experiments are given in Fig. 5 . The samples were maintained at a high humidity (about 90 per cent) for more than a month prior to December 4, 1913, when the

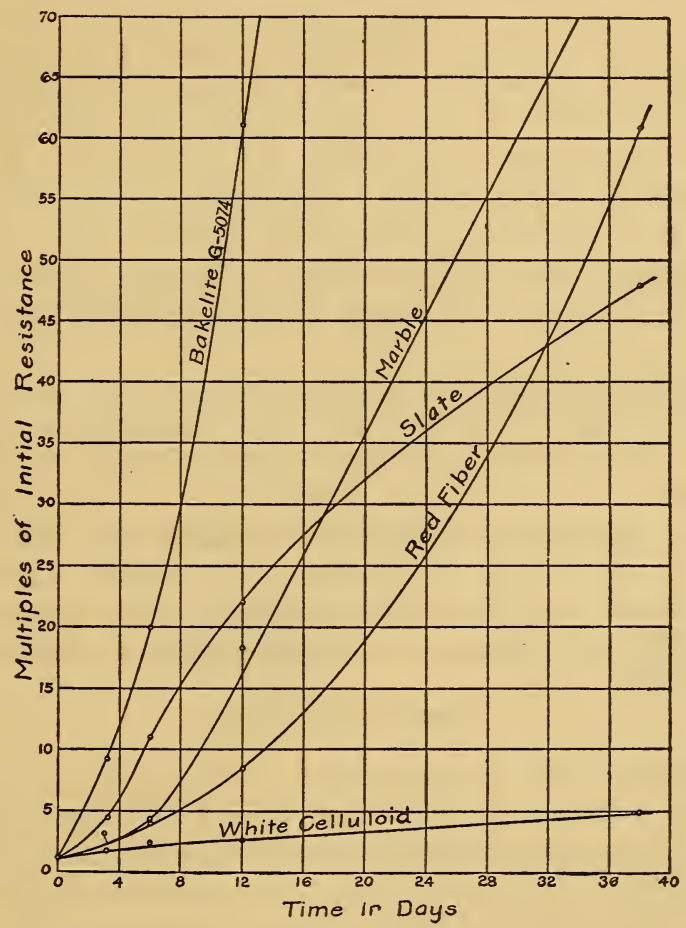

FIG. 5.-Increase in the volume resistivity of certain materials caused by a loss of absorbed moisture

humidity of the tank was decreased to 25 per cent and maintained at this humidity and a temperature of $25^{\circ} \mathrm{C}$ until January $\mathrm{I} 2$, 1914. Measurements were made at the times indicated in the figure. In many cases there was a progressive increase in the resistance and for most of these samples an equilibrium had not 
been reached at the end of 40 days. Of the five curves given, celluloid shows the least change, while bakelite No. $\mathrm{G}_{5074}$ shows the largest. The celluloid has five times the resistance which it initially had, while the bakelite has over 300 times as much. This sample of bakelite contained talc as a filler. A more complete statement of its composition will be found in Table 4, page 399.

It is well known that marble, slate, and hard fiber absorb water in considerable quantities. The curves show that they lose this water very slowly. In the case of slate it is apparent that a definite value is being approached, but for some of the others no such statement can be made. The indefiniteness of the volume resistivity of materials which absorb water is very apparent. Where changes take place as slowly as in these cases it is not feasible to determine the change of volume resistivity with humidity.

A number of samples were measured besides those whose curves are given in Fig. 5. In some cases very interesting results were obtained. It is known that shellac absorbs moisture to an appreciable extent, yet no change of resistivity with humidity was observed. In the case of glass the results upon one sample indicate a slight change of resistivity with humidity, but it is too small to announce with certainty. Some of the molding compounds-electrose, gummon, and molded mica-showed no measurable change.

\section{EFFECT OF VOLTAGE}

Observations which have been made on the change of the volume resistivity of insulators with voltage show a wide variation in the results. Many observers have found that the resistance of certain insulators which they were studying did not depend on the voltage, while others have found that the resistance decreases as the voltage increases. It is to be expected that there will be a decrease in the resistance when the voltage is so high that breakdown is approaching, but in some cases it has been observed when very far removed from breakdown. The literature on this subject is so large, that no adequate review of it can be undertaken here. Mention will be made of only one article. 
Evershed ${ }^{4}$ has investigated certain porous materials such as paper and cotton cloth. For very low voltages, he finds that the resistance decreases rapidly with increasing voltage, becomes nearly stationary at higher values, and again drops rapidly at still higher values. In the region of low voltages, he finds that if the voltage is increased by a factor of to the resistat.ce decreases by a factor of about 2.2. He has developed a theory for this change which depends upon the condensation of moisture in the pores of the material.

Measurements upon similar materials in this laboratory confirm his results. However, the materials used in this investigation are of such a different character that similar results are not to be expected. The results upon a number of materials are given in Table $\mathrm{I}$. It will be seen that only in one-third of the specimens is there any appreciable change in going from 50 to 500 volts, and of these the majority are known to be porous. In the case of opal glass there was an increase in resistance with increasing voltage and while this was confirmed by several measurements, no other material was found which gave a similar result.

TABLE 1

Table Showing Change of Volume Resistance with Voltage

\begin{tabular}{|c|c|c|c|c|c|}
\hline Matarial & $\begin{array}{c}\text { Thick- } \\
\text { ness of } \\
\text { specimen }\end{array}$ & $\begin{array}{l}\text { Ratio of } \\
\text { resistance } \\
\text { at } 50 \text { volts } \\
\text { to tine } \\
\text { resistance } \\
\text { at } 500 \\
\text { volts }\end{array}$ & Material & $\begin{array}{l}\text { Thick- } \\
\text { ness of } \\
\text { specimen }\end{array}$ & $\begin{array}{l}\text { Ratio of } \\
\text { resistance } \\
\text { at } 50 \text { volts } \\
\text { to the } \\
\text { resistance } \\
\text { at } 500 \\
\text { volts }\end{array}$ \\
\hline & $\mathrm{cm}$ & & & $\mathrm{cm}$ & \\
\hline Yellow electrose.............. & 1.27 & 1.0 & Bakelite No, $150 \ldots . . . . . . . .$. & 0.97 & 1.0 \\
\hline Hemit..................... & 0.73 & 1.0 & Bakelite No.151............ & .98 & 1.0 \\
\hline Tegit................. & .78 & 1.0 & Bakelite No.190.............. & .96 & 1.0 \\
\hline Gummon................ & .62 & 1.0 & Bakelite No.192............. & .99 & 1.1 \\
\hline Red fiber................... & 1.27 & 1.0 & Bakelite No. G5074 . . . . . . . . . . & .95 & 1.9 \\
\hline Hard fiber................ & 1.23 & 1.0 & J-P Bakelite............ & .60 & 2.0 \\
\hline Redmonite................ & .13 & 1.0 & Slate.............. & (............. & 1.1 \\
\hline Paraffined maple. . . . . . . . . . . . & 2.3 & 1.0 & Marble: & & \\
\hline Parafined poplar. ............ & 1.8 & 1.0 & Pink Tenressee. ......... & 2.25 & 1.4 \\
\hline Yellow condensite........... & 1.32 & 1.0 & Blua Vermoni. . . . . . . . . . & 2.3 & 2.0 \\
\hline Black condensite............... & 1.28 & 1.0 & Italian .......................... & 2.2 & 2.5 \\
\hline Bakelite No. $140 \ldots . . . . . . .$. & .96 & 1.0 & Opal glass . . . . . . . . . . . . & .17 & .7 \\
\hline Balrelite No.141... . . . . . . . . . & .99 & 1.0 & & & \\
\hline
\end{tabular}


No results are given for the very best insulators since, as will be shown later, the effect of dielectric absorption is so large that any possible change of resistance with voltage is entirely masked.

\section{EFFECT OF TEMPERATURE}

The variation of the volume resistivity of insulators with temperature has been the subject of many investigations. The majority of these have used a wide range of temperatures and have only estimated the change in resistivity corresponding to the ordinary fluctuation of room temperature by extrapolation from much higher temperatures.

A large number of the ordinary insulators were investigated by Dietrich ${ }^{5}$ between the temperatures of $20^{\circ}$ and $200^{\circ} \mathrm{C}$., though the measurements at temperatures below $50^{\circ} \mathrm{C}$. were not very satisfactory. He found that the results could be approximately represented by the formula ${ }^{\circ}$

$$
R_{t}=R_{o} e^{\frac{-q t}{273(273+t)}}
$$

where $R_{t}$ is the resistance at any temperature $t, R_{0}$ the resistance at zero centigrade and $q$ a constant which depends upon the material. The values of $q$ lie between 4000 and 25000 . For the range $20^{\circ}$ to $30^{\circ}$, the smaller value of $q$ corresponds to a decrease in the resistance of 50 per cent, while for the larger value of $q$, the resistance at $20^{\circ}$ is 17 times as large as at $30^{\circ}$.

In Table 2 are given the values found in this laboratory. The range of temperature has been from $20^{\circ}$ to $30^{\circ} \mathrm{C}$. in every case. The substances used are sufficiently representative to indicate what may ordinarily be expected in this range.

\footnotetext{
5 Concerning the conductivity of electric insulators Diss. Göttingen, 1909, An abstract is to be found in Phys. Zs., 11, p. 187; 1910.

${ }^{6}$ From considerations of the electron theory, Koenigsberger \& Reichenhein (Phys. Zs., 7, p. 570; 1906 derived the formula

$$
R_{t}=R_{0}\left(\mathrm{x}+a t+\beta t^{2}\right) \frac{-q t}{273(273+t)}
$$

for the change of resistivity with temperature for any body. The terms containing $a$ and $\beta$ are negligible in the case of insulators. The formula of Rausch \& Hinrischen (Zs. für Elektrochemie 14, p. 4r; I908) is equivalent to this modified formula. Most of the work which has been done to check these formulas has been at temperatures above $100^{\circ} \mathrm{C}$.
} 
TABLE 2

Table showing the Decrease of Volume Resistivity with Increasing Temperature

$\left[\rho_{20}=\right.$ Volume resistivity at $20^{\circ} \mathrm{C} ; \rho_{30}=$ Volume resistivity at $\left.30^{\circ} \mathrm{C}\right]$

\begin{tabular}{|c|c|c|c|c|c|}
\hline Sample & $\rho_{30}$ & $\rho_{20} / \rho_{30}$ & Samplo & $\rho_{30}$ & $\rho_{20} / \rho_{30}$ \\
\hline Sealing wax... & $1.9 \times 10^{16}$ & 0.9 & German glass..... & $2.0 \times 10^{18}$ & 2.5 \\
\hline Mica (India ruby, slightly & & & Halowax........ & $1.3 \times 10^{13}$ & 2.5 \\
\hline spotted) $\ldots . . . \ldots \ldots \ldots \ldots$ & $1.0 \times 10^{17}$ & 1.0 & Yellow electrose (D). & $3.3 \times 10^{16}$ & 2.6 \\
\hline Insulate No. 2.... & $8.4 \times 10^{15}$ & 1.0 & Bakelite No. G5074. . & $2.3 \times 10^{10}$ & 2.6 \\
\hline Hemit (a).......... & $2.1 \times 10^{10}$ & 1.2 & Red fiber............. & $7.8 \times 10^{9}$ & 2.6 \\
\hline G. E. No. 55A.......... & $1.3 \times 10^{15}$ & 1.2 & Bakelite No. L558... & $1.0 \times 10^{16}$ & 2.6 \\
\hline Moulded mica ............. & $2.0 \times 10^{15}$ & 1.2 & Mica (India ruby, stained).. & $2.2 \times 10^{13}$ & 2.7 \\
\hline Mica (brown African clear). & 1. $7 \times 10^{15}$ & 1.2 & Opal glass........... & $5.0 \times 10^{11}$ & 2.8 \\
\hline Hemit (b) ............... & $5.7 \times 10^{9}$ & 1.4 & Yellow condensite..... & $1.7 \times 10^{10}$ & 2.9 \\
\hline Tegit.......... & $1.9 \times 10^{12}$ & 1.4 & Black condensite... & $4.8 \times 10^{10}$ & 2.9 \\
\hline Gummon....... & $3.4 \times 10^{12}$ & 1.4 & Tetrachlornaphthalene. & $1.7 \times 10^{13}$ & 2.9 \\
\hline Shellac......... & $1.2 \times 10^{16}$ & 1.5 & Glyptol........... & $7.4 \times 10^{15}$ & 3.0 \\
\hline Ivory............. & $1.5 \times 10^{8}$ & 1.6 & Dielectrite......... & $2.2 \times 10^{12}$ & 3.0 \\
\hline J-P Bakelite ....... & $1.2 \times 10^{10}$ & 1.6 & Hard fiber....... & $1.0 \times 10^{10}$ & 3.2 \\
\hline Unglazed porcelain... & $2.2 \times 10^{14}$ & 1.6 & Plate glass. .................. & $1.0 \times 10^{13}$ & 3.2 \\
\hline Yellow stabalite.... & $4.3 \times 10^{13}$ & 1.6 & German glass (special).. & $5.0 \times 10^{13}$ & 3.5 \\
\hline G. E. No. $40 \ldots \ldots$. & $6.7 \times 10^{14}$ & 1.6 & Bakelite No. $4 \ldots . .$. & $3.3 \times 10^{9}$ & 3.6 \\
\hline White celluloid..... & $1.4 \times 10^{10}$ & 1.8 & Bakelite No. $190 . .$. & $4.2 \times 10^{10}$ & 3.6 \\
\hline Murdock No. 200... & $3.2 \times 10^{15}$ & 1.8 & Bakelite No. $150 \ldots$... & $1.9 \times 10^{12}$ & 3.6 \\
\hline Murdock No. 201... & $5.2 \times 10^{15}$ & 1.8 & Paraffined maple...... & $1.9 \times 10^{10}$ & 3.6 \\
\hline Mica (clear)......... & $1.1 \times 10^{17}$ & 2.0 & Paraffined poplar..... & $2.3 \times 10^{11}$ & 3.6 \\
\hline Parawax................ & $2.6 \times 10^{13}$ & 2.0 & Rosin ................... & $1.7 \times 10^{16}$ & 3.6 \\
\hline Redmonite No. 183, 1.. & $4.7 \times 10^{13}$ & 2.0 & Kavalier glass......... & $2.0 \times 10^{15}$ & 4.5 \\
\hline Black electrose. .......... & $6.0 \times 10^{18}$ & 2.0 & Sulphur................ & $3.9 \times 10^{16}$ & 4.9 \\
\hline Vuicabeston (a)....... & $8.4 \times 10^{9}$ & 2.3 & G. E. No. 55R............... & $5.9 \times 10^{15}$ & 5.1 \\
\hline Yellow electrose (L)........ & 4. $7 \times 10^{15}$ & 2.3 & Bakelite No. 5200 RGR..... & $1.2 \times 10^{11}$ & 5.3 \\
\hline Bakelite No. $140 . . .$. & $7.5 \times 10^{6}$ & 2.4 & Khotinsky cement.... & $2.1 \times 10^{14}$ & 11.0 \\
\hline Bakelite micarta ............ & $2.7 \times 10^{10}$ & 2.4 & Yellow beeswax............. & $4.0 \times 10^{14}$ & 16.0 \\
\hline
\end{tabular}

NoTE.-Values are for individual samples. For the volume resistivity of materials, as determined by measurements upon several samples, see Table 3 .

\section{EFFECT OF DIELECTRIC ABSORPTION}

The system of two opposite electrodes separated by a dielectric such as that used in measuring the volume resistivity of insulators may also be considered as a condenser. Hence, at the instant of closing the circuit the current will be largely due to the displacement through the dielectric, but this will become negligible in a few thousandths of a second. Also as in the case of all condensers using solid dielectrics there will continue to flow for some time a 
current which is absorbed by the dielectric. This absorption current decreases with the time, approximately following an exponential law, and may not become negligible for several hours.

This absorption current is superimposed upon the current due to conduction. If the conduction current is large relative to the maximum value of the absorption current, the apparent resistance (ratio of electromotive force to the total current) is independent of the length of time that the electromotive force is applied. But if the conduction current is small, the absorption current may, for a time after the application of the electromotive force, be larger than the conduction current. The resistance can then be obtained only by applying the electromotive force for a sufficiently long time to make the absorption current negligible.

While accurate data are not as yet available concerning the absorption current, it is possible to get some idea of its magnitude, and hence to estimate at what point the absorption becomes an important factor. Immediately after applying the electromotive force the absorption current may be relatively large, but it decreases rapidly so that at the end of one minute the quantity absorbed per second is usually between $\mathrm{r} / \mathrm{r} 00$ and $\mathrm{I} / \mathrm{r} 00$ ooo of the quantity which was displaced through the dielectric. If we assume that the dielectric constant is five, then the absorption current at the end of one minute in the case of a cubic centimeter of the material having electrodes on opposite faces to which is applied a potential difference of one volt lies between $0.5 \times 1 \mathrm{ro}^{-14}$ and $0.5 \times 1 \mathrm{IO}^{-17}$ ampere. In order that the conduction current shall be at least ten times as large as this, the resistivity must be less than $2 \times 10^{13} \mathrm{ohms}$ in the first case, and $2 \times 10^{16}$ ohms in the second case.

Hence in those cases where the volume resistivity is less than about $\mathrm{IO}^{13}$ ohms, the absorption current gives no error greater than ro per cent, provided the resistance is measured at the end of a minute. However, if the resistivity is above $\mathrm{rO}^{13} \mathrm{ohms}$, measurements must be made with different time intervals in order to determine when the absorption current becomes negligible. If the resistivity is greater than $\mathrm{IO}^{16} \mathrm{ohms}$, the absorption current at the end of one minute will probably equal the conduction current and may be much larger. In such cases, it is necessary 
to apply the voltage for a much longer time before the true conduction current can be obtained.

In Fig. 6 are curves showing the change of the apparent resistivity with time for two insulators having a resistivity greater than $10^{17} \mathrm{ohm}$-cms. In the case of hard rubber it will be seen that even at the end of half an hour the absorption current is more than ten times the conduction current. Even at the end of 18 hours we are not certain that the absorption current is negligible. For fused quartz the curve indicates that the change in the apparent resistivity continues for a long time. At the end of an hour the resistivity was so high as to be just measurable. At the end of 18 hours the resistivity was too high to measure, certainly above $5 \times 10^{18}$.

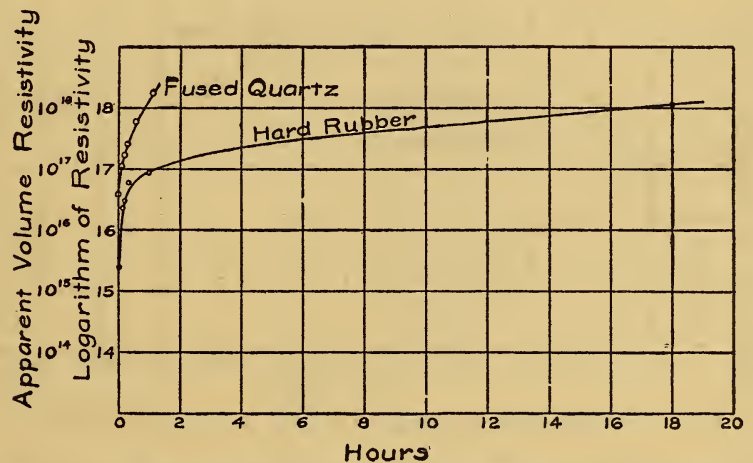

Fig. 6.-Effect of dielectric absorption upon the apparent resistivity

In Fig. 7 are given curves of the change of the apparent resistivity with time for a material at two different temperatures. The shape of the curves is somewhat different, showing that temperature modifies the absorption curves. At $30^{\circ}$ the resistance had reached its maximum in about two hours, while at $20^{\circ}$ the curve had an upward tendency at the end of seven hours.

\section{VALUES OF THE VOLUME RESISTIVITY}

The values of the volume resistivity of a large number of insulators arranged in order of their resistivities are given in Table 3 . While measurements were made at various times during the course 
of this investigation, yet the final measurements were made in March, April, and May, I9I4. The specimens had been kept in the laboratory during the winter, and as the humidity of heated rooms is always low, the amount of moisture in those materials which absorb water was as low as will normally be found.

The determinations were made at room temperature, $22^{\circ} \mathrm{C}$. Except in the case of some of the insulators having very high resistivity, the voltage was applied for a sufficiently long time to make the absorption current negligible. As time did not permit the determination of the resistivity for all materials, the apparent resistivity after the voltage has been applied for $x_{5}$ minutes is given in certain cases. These are indicated by an asterisk. Very

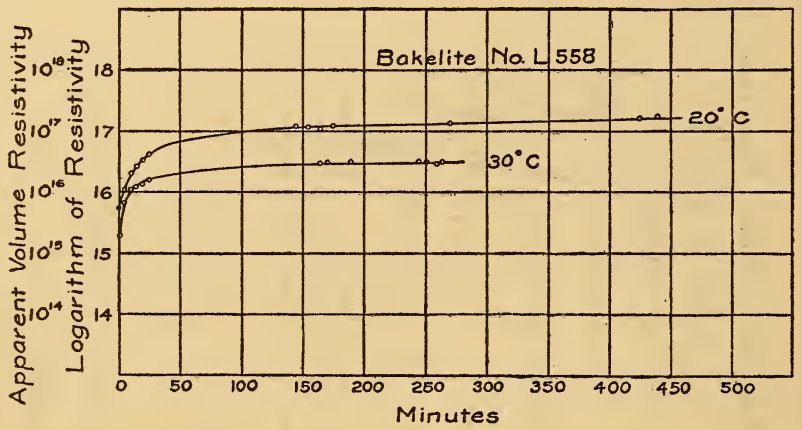

FIG. 7.-Effect of dielectric absorption upon the apparent resistivity

few of the materials are so uniform that two samples will give values of the resistivity as close as Io per cent, while a factor of Io or even more is not infrequent. Hence, it did not seem desirable to give more than one significant figure in the results, though in the measurements upon individual samples two significant figures were obtained whenever possible.

In Table 8 (appendix) the values of the resistivity are repeated, but the materials are arranged in alphabetical order. In addition are given values as obtained by other observers. This comparison may be of use in showing the variation that may be obtained with different samples, different conditions, and different methods of measurement. 
TABLE 3

Volume Resistivity of Solid Dielectrics

[Materials arranged in order of decreasing resistivity]

\begin{tabular}{|c|c|c|c|}
\hline Materiai & Resistivity & Material & Resistivity \\
\hline & Ohm-centimeters & & Ohm-centimeters \\
\hline Special paraffin.............. & Over $5000 \times 10^{15}$ & German giass................ & $50 \times 10^{12}$ \\
\hline Ceresin...$\ldots \ldots \ldots \ldots \ldots$ & Over $5000 \times 10^{15}$ & Paraffined mahogany........ & $40 \times 10^{13}$ \\
\hline Fused quartz.................. & Over $5000 \times 10^{15}$ & Stabalite .................... & $30 \times 10^{12}$ \\
\hline Hard rubber.................. & $1000 \times 10^{15}$ & Plate glass. ..................... & $20 \times 10^{12}$ \\
\hline Clear mica................... & $200 \times 10^{15}$ & Hallowax No. 1001........... & $20 \times 10^{12}$ \\
\hline *Sulphur................... & $100 \times 10^{15}$ & Dielectrite................. & $5 \times 10^{12}$ \\
\hline 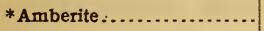 & $50 \times 10^{15}$ & Bakelite No. 5199 RGRB ... & $5 \times 10^{12}$ \\
\hline$*$ Rosin. .................. & $50 \times 10^{15}$ & Bakelite No. 150............. & $4 \times 10^{12}$ \\
\hline * Mica (India ruby slightly & & 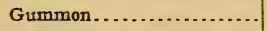 & $3 \times 10^{12}$ \\
\hline stained) ................... & $50 \times 10^{15}$ & Tegit...................... & $2 \times 10^{12}$ \\
\hline G. E. No. 55 R................. & $40 \times 10^{15}$ & Opal glass........................ & $1 \times 10^{12}$ \\
\hline Hallowax No. 5055 B........ & $20 \times 10^{15}$ & Paraffined poplar............ & $500 \times 10^{\circ}$ \\
\hline Bakelite No. L $558 . . . . . . . . .$. & $20 \times 10^{15}$ & Bakelite No. G 5200 RGR... & $400 \times 10^{9}$ \\
\hline * Electrose No. 8........... & $20 \times 10^{15}$ & Bakelite No. 1.............. & $200 \times 10^{\circ}$ \\
\hline *Parowax (paraffin) ......... & $10 \times 10^{15}$ & Bakelite No. $190 . . . . . . . .$. & $100 \times 10^{9}$ \\
\hline Glyptol....................... & $10 \times 10^{15}$ & Italian marble............... & $100 \times 10^{9}$ \\
\hline *Shellac................... & $10 \times 10^{15}$ & Bakelite micarta. ............ & $50 \times 10^{0}$ \\
\hline Kavalier glass............ & $8 \times 10^{16}$ & Bakelite No. G $5074 \ldots . . . .$. & $40 \times 10^{9}$ \\
\hline *Insulate No. $2 \ldots . . . . . . . .$. & $8 \times 10^{15}$ & Black condensite ........... & $40 \times 10^{9}$ \\
\hline *Sealing wax................ & $8 \times 10^{15}$ & Yellow condensite.......... & $40 \times 10^{9}$ \\
\hline *Yellow electrose........... & $5 \times 10^{15}$ & Paraffined maple........... . . & $30 \times 10^{9}$ \\
\hline *Duranoid.................. & $3 \times 10^{15}$ & White celluloid.............. & $20 \times 10^{9}$ \\
\hline *Murdock No. $100 \ldots . . . .$. . & $3 \times 10^{15}$ & J-P Bakelite ............. & $20 \times 10^{9}$ \\
\hline *Yellow beeswax............ & $2 \times 10^{15}$ & Hard fiber.................. & $20 \times 10^{9}$ \\
\hline Khotinsky cement. . . . ....... & $2 \times 10^{15}$ & Black galalith . .............. & $20 \times 10^{9}$ \\
\hline Mica (brown African clear).. & $2 \times 10^{15}$ & Lavite..................... & $20 \times 10^{9}$ \\
\hline *G. E. No. $40 \ldots \ldots . . . . .$. & $1 \times 10^{15}$ & White galalith................ & $10 \times 10^{9}$ \\
\hline *G. E. No. 55 A............. & $1 \times 10^{15}$ & Hemit..................... & $10 \times 10^{9}$ \\
\hline *Moulded mica.............. & $1 \times 10^{15}$ & Red fiber . . . . . . . . . . . . . . . & $5 \times 10^{9}$ \\
\hline Unglazed porcelain........... & $300 \times 10^{12}$ & Pink Tennessee marble..... & $5 \times 10^{9}$ \\
\hline Redmonite No. 157,4,........ & $200 \times 10^{12}$ & Blue Vermont marble....... & $1 \times 10^{9}$ \\
\hline Black electrose.............. & $100 \times 10^{12}$ & 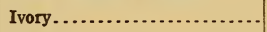 & $200 \times 10^{6}$ \\
\hline Tetrachlornaphthalene...... & $50 \times 10^{12}$ & Slate....................... & $100 \times 10^{6}$ \\
\hline Mica (India ruby stained)... & $50 \times 10^{12}$ & Bakelite No. $140 . . . . . . . .$. & $20 \times 10^{6}$ \\
\hline
\end{tabular}

* Apparent resistivity taken after the voltage had been applied for $1_{5}$ minutes.

In making, tabulating, and interpreting the thousands of observations here presented, the greatest care has been exercised. At least two determinations have been made on each material, possible sources of error have been carefully considered, and, whenever feasible, two entirely different methods have been employed 
with each sample. Also the results obtained have been compared as far as possible with those of other observers. It is our belief that the errors which finally remain are comparatively few.

\section{SURFACE LEAKAGE}

The current which flows between two conductors, maintained at different potentials and insulated from each other by a solid material, is made up of two parts-that which flows through the insulator proper, and that which flows through a film of moisture or other conducting material on the surface of the insulator. The relative importance of these will depend on the resistance of the two paths. Since water, even if very pure, conducts much better than the ordinary solid insulators, a very thin film of water may have much less resistance than the insulator.

Before discussing these further, some definitions are desirable. The volume resistivity, $\rho$, of a material has already been defined as the resistance between two opposite faces of a centimeter cube. From the relationship between the size and resistance of a specimen it follows that

$$
R=\frac{\rho l}{A} \text { or } \rho=\frac{R A}{l}
$$

where $R$ is the resistance of a cylinder of cross section $A$ and length $l$. By analogy we shall define the surface resistivity as the resistance between two opposite edges of a surface film which is one centimeter square. If the film is uniform over a surface

$$
\sigma=\frac{R^{\prime} b}{l}
$$

where $\sigma$ is the surface resistivity and $R^{\prime}$ the resistance of a rectangle of the film of length $l$ and breadth $b$. If the thickness of the film is $t$, the volume resistivity of the film will be

$$
\rho^{\prime}=\frac{R^{\prime} b t}{l}=\sigma t
$$

or $\sigma=\rho^{\prime} / t$. 
Since $\sigma$, the surface resistivity, depends upon the thickness of the film, it is not a property of the material of the film, and the term "resistivity," which is generally used to express the property of a material, can not strictly be applied. However, since both the thickness $t$ and the volume resistivity $\rho^{\prime}$ of the surface film depend, under any given conditions, upon the material on which it is deposited, surface resistivity may be considered as a property of the material on which the film is deposited. Thus we will speak of the surface resistivity of glass, hard rubber, etc., though these mateirals only serve for condensing the moisture and do not carry any of the current.

It is quite impossible to devise a means for measuring the resistance of the surface film by itself, since some of the current will always flow through the insulator on which the film is deposited. However, by knowing the volume resistivity, a correction can be applied to the measured resistance to give the surface resistance. In only a few cases is this correction appreciable. A discussion of this correction is given on page $4 \mathrm{II}$, et seq.

It is sometimes convenient to have a term to express the total resistance between two conductors insulated by a solid dielectric. We shall call this the leakage resistance. We shall define the leakage resistivity as the resistance between two conductors, each I cm square, when they are placed I cm apart on an insulator I $\mathrm{cm}$ thick. While the leakage resistivity will in all cases be less than the surface resistivity, yet the difference between the two will usually be far less than the errors of measurement.

Since our measurements show that the surface film is largely moisture condensed from the surrounding atmosphere, the atmospheric humidity will largely determine the surface resistivity of a material. However, it is to be expected that the temperature of the specimen will be of some influence. Also since chemical changes are often produced by exposure to light, the surface resistivity of a material may be affected by such an exposure.

It might be expected that the applied voltage would affect the surface resistance, but, though a wide range of voltage was used in some cases, no change in resistance was ever observed. At high humidities the resistance frequently changed by as much as 
a factor of ro in the first minute after closing the key-increasing with some samples, decreasing with others. No cause for this behavior has been found. The value at the end of one minute has been taken as the correct value.

\section{EFFECT OF HUMIDITY}

In order to determine the effect of humidity upon the surface resistance of a material one or more samples were placed in the case already described, and their resistance measured at different humidities. While the procedure varied somewhat as the work progressed or as occasion demanded, the following method is the one usually employed.

A number of samples (50 was the maximum) were placed in the case and their leads brought out through the paraffin top. The thermostat was adjusted to maintain the temperature at about $25^{\circ}$ in winter and $29^{\circ}$ in summer. About $500 \mathrm{cc}$ of sulphuric acid solution of the proper density to give the desired humidity was placed in a crystallizing dish in the bottom of the case and the case carefully sealed with paraffin. Measurements of the insulation resistance were made on the following day, after the samples had been kept in air at a given humidity for 18 or 20 hours. The case was then opened, the acid replaced by some of a different density, and the cycle repeated. This was continued until sufficient observations had been made.

The acid solutions were so chosen as to give relative humidities of $25,50,70,85$, and 95 per cent. In one case phosphorous pentoxide was used, giving a relative humidity of less than o.I per cent. In all cases the resistance was first measured at 25 per cent humidity. The usual procedure was then to increase the humidity by the steps indicated above until 95 per cent was reached, when the humidity was again lowered to 25 per cent.

After computing and tabulating the results, a curve was plotted for each sample showing its change of surface resistivity with the humidity. Nearly two hundred such curves have been plotted. From these, the curves given in Figs. ro to 24 were selected. They cover practically all of the materials investigated, and were chosen as being representative of these materials. 
Before discussing these curves, it will be desirable to consider the length of time necessary for the surface resistance of a substance to become stationary after a change of humidity of the surrounding air. In Fig. 8 is a curve showing the time rate of change of surface resistance of clean hard rubber when the humidity is increased from 50 per cent to 93 per cent. In this figure it should be noticed that the ordinates are the logarithms of the resistivities. It will

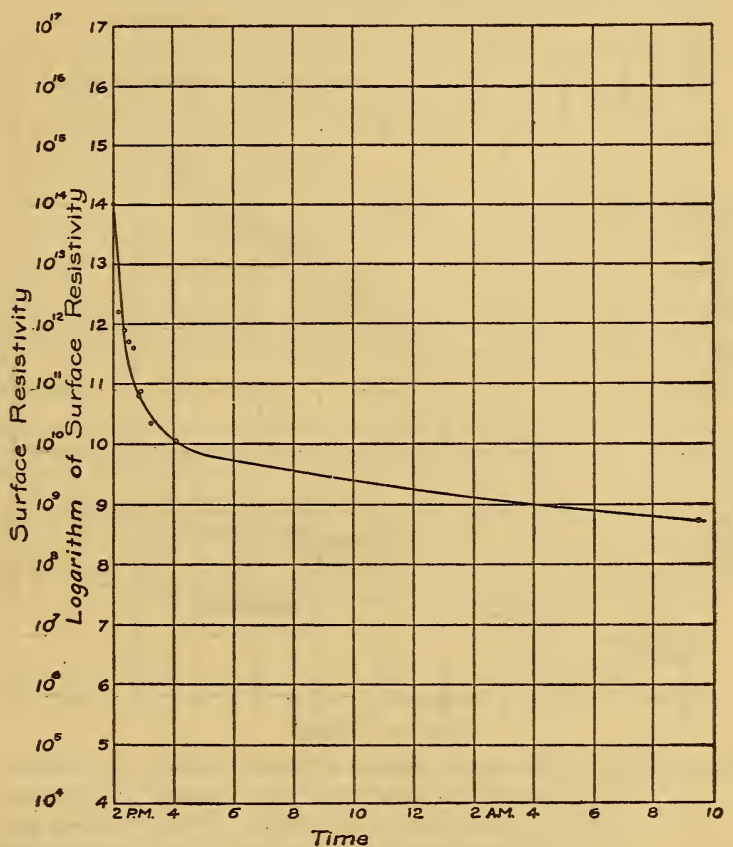

FIG. 8.-Curve showing the change in surface resistance with time of a piece of hard rubber when the humidity is increased from 50 to 93 per cent

be seen that the resistance changes rapidly for the first two or three hours, when the change becomes slower and is approximately exponential, as is shown by the fact that the curve is nearly a straight line when plotted as indicated above. While the change is comparatively slow after two or three hours, yet a steady state has not been reached at the end of 19 hours. 
The change of resistance for three materials over longer periods of time is shown in Fig. 9. The scale in this case is different than in the preceding case, the ordinates being multiples of the initial resistance. The samples had been in air of 95 per cent humidity, then the humidity was lowered to 29 per cent. After remaining at this humidity for 48 hours, the initial reading was taken. The hard rubber which had deteriorated on account of exposure to

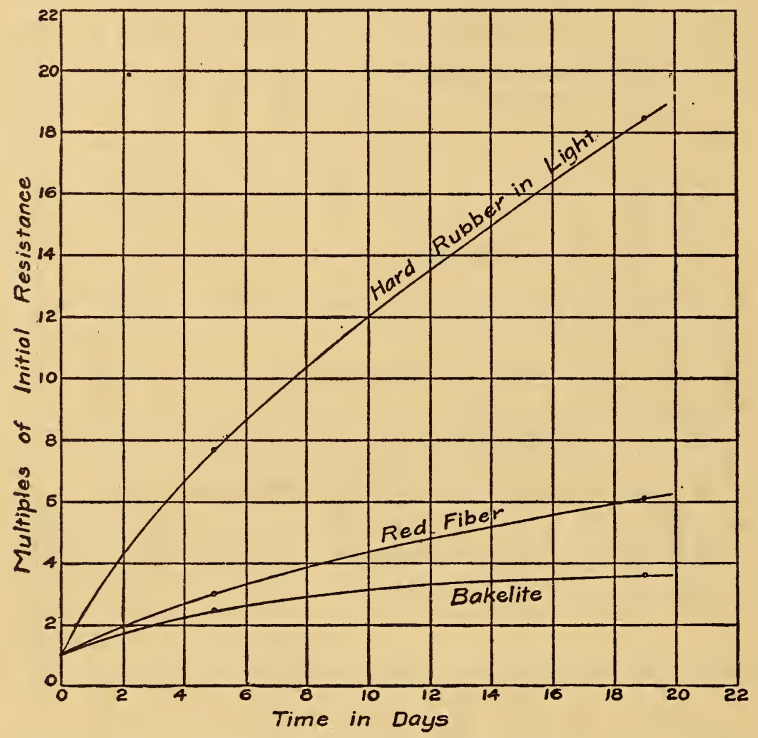

FIG. 9.-Curves showing the increase of surface resistance of specimens which had been in air at 95 per cent humidity and were then placed in air at 20 per cent humidity. The first readings were not taken until the specimen had been at the lower humidity for 48 hours

sunlight showed a very marked increase in the resistance and the maximum had not been reached at the end of 19 days. The other curves were selected as representing the change which takes place, when most insulating materials are subjected to a change in the humidity of the surrounding air. They show that precise results are of little value in the practical use of insulators. 
Except in a few cases where it was desired to show the effect of cleaning, the samples were cleaned in the same manner and to the same extent as would be done in practical work; i. e., they were wiped with a cloth or dusted with a brush. The effect of traces of materials left on the surface will be discussed later.

All of the curves of surface resistivity given in Figs. 1o to 24 are plotted on the same scale, so that they can be readily compared. In order to make this possible, the logarithm of the surface resistivity is plotted as ordinate, so that the actual values of the surface resistivity progress by powers of ro. In this manner very large changes of resistance can be shown on one sheet. The abscissa is the per cent of relative humidity.

In order that the reader may judge for each sample concerning the lag of the surface resistivity after a change in the humidity of the surrounding air, those values which were taken with increasing humidity are indicated upon the curves by open circles, while those values which were taken with decreasing humidity are indicated by solid circles.

To economize space and to facilitate comparison of one curve with another it has been necessary to place several curves on one sheet. Where uncertainty might exist as to the curve to which a given point belongs, a fine line is drawn to connect the point with the curve. 


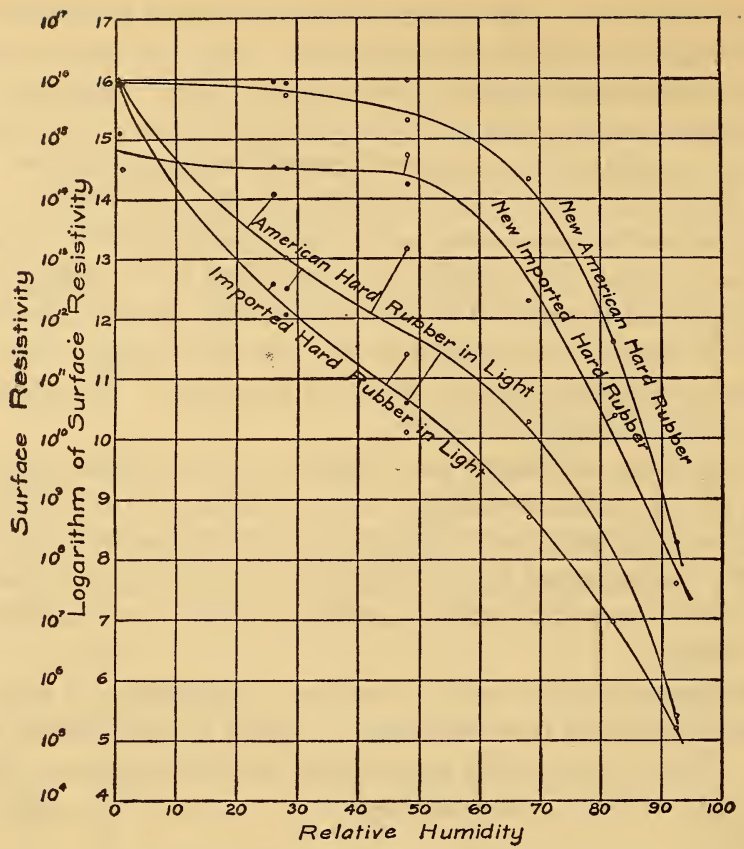

FIG. I0.-Change of surface resistivity with humidity of samples of hard rubber before and after exposure to sunlight

In Fig. ro are given curves of four samples of hard rubber. Two had been protected from the action of the light, while two had been exposed to strong sunlight for several months. It will be noticed that between 0 and 50 per cent humidity the new rubber changes but little, while above that the changes are very pronounced. The surface resistivity is one million times as large at 50 per cent humidity as at 90 per cent. With the rubber which had been exposed to the light the changes in resistance continue until the lowest humidity is reached. The resistance of these specimens at very low humidity is ro $^{11}$ times or one hundred billion times as great as is the resistance at 95 per cent humidity. It will be seen that very slight changes of the humidity will affect the insulation in a very marked manner.

Other samples of hard rubber have been tested, and those given may be taken as representative of the best grades of hard rubber. Of the two kinds whose curves are given, the imported rubber has a finer texture, and can be worked and polished better than the American rubber. However, all the tests upon the insulation show that the American rubber is the better insulator. This shows how difficult it is to connect the insulating properties with the mechanical properties. 


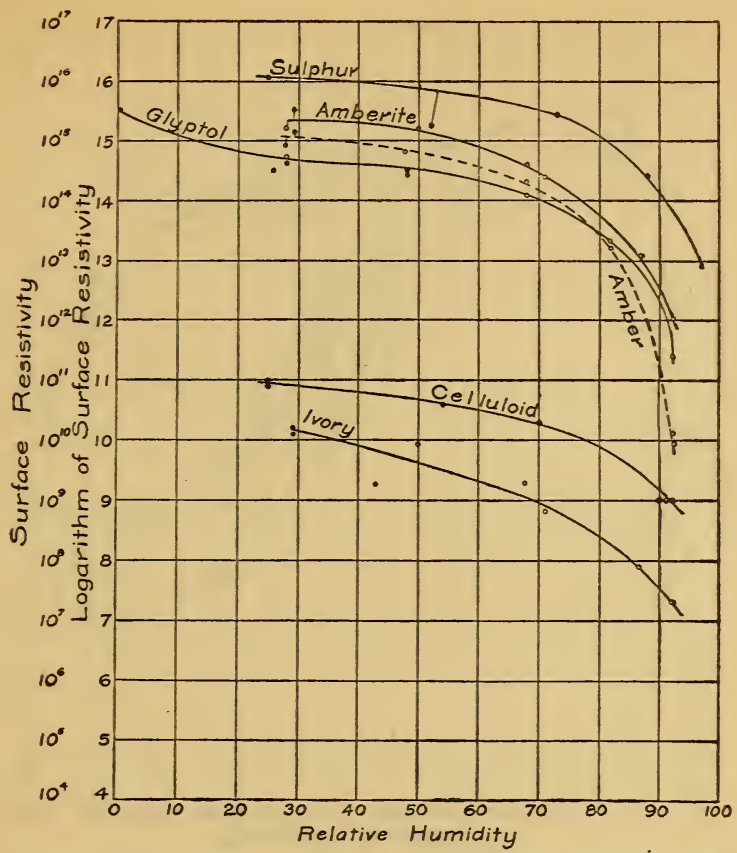

FIG. Ir. - Change of surface resistivity with humidity of sulphur, ivory, and amber-like materials

Three of the curves given in Fig. II are for amber and amber-like materials. The sample of amber was a piece of clear native amber, the surface of which had been carefully polished. This is one of the few cases where only a single sample was measured. The amberite was a sample of the material which is made by compressing scrap amber. This material under the name of amberite or ambroid is now extensively used and it is apparent that so far as surface leakage is concerned it is the equal of native amber. In working with this material it was found that the specimen must be well cleaned to get the best results. Apparently handling with the fingers leaves a deposit of various deliquescent salts which condense moisture and lower the conductivity at the higher humidities. The glyptol is an artificial resin furnished by the research department of the General Electric Co. It resembles amber.

Three different samples of sulphur were tested. They showed wide variations. The curve which is given lay between those of the other samples. Threlfall states that sulphur heated just to its melting point and then cooled has better insulating properties than that which has been heated to a higher temperature before cooling. The sample of celluloid was a piece of clear celluloid. Several samples were tested having various amounts of coloring matter and filler, but the surface resistivity was substantially the same for all. Ivory can not be considered as a material having high insulating properties. A substitute, white galalith, is somewhat better. (See Fig. 22.) 


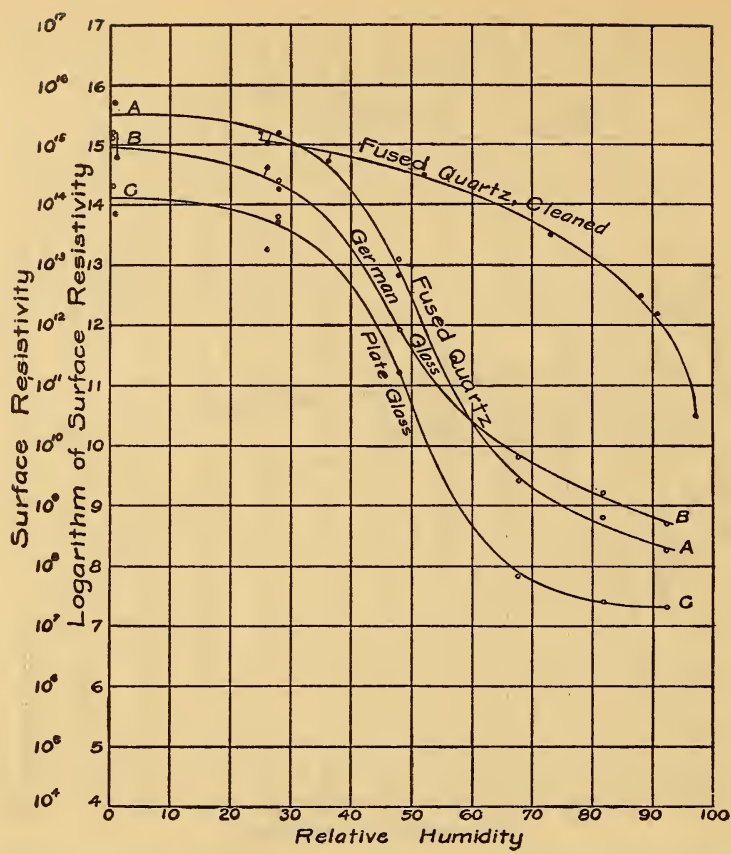

FIG. 12.-Change of surface resistivity with humidity of glass and quartz

In Fig. I2 the behavior of fused quartz and certain kinds of ordinary glass is shown. Several samples of quartz were tested, but the two curves given were for the same sample. The sample from which the curve marked "fused quartz" was obtained was cleaned in the same manner as other samples, but no special care was taken. It was carefully cleaned in strong chromic acid, washed in distilled water, and dried before obtaining the curved marked "fused quartz, cleaned." The surface was thus well freed from foreign substances. At low humidities there was no difference in the two specimens. At higher humidities there is a large difference, amounting to as much as a factor of ten thousand. This may be due to the lack of condensation of moisture on the cleaned specimen or to the fact that the water which is condensed has a lower conductivity. Doubtless both of these causes play a part.

The statement is sometimes made that the method of manufacture of fused quartz very decidedly affects the insulating properties of the product. This has not been substantiated by the results obtained in the course of this investigation. A piece of old quartz tubing made by Heraeus in 1904 was measured at the same time and under the same conditions as the sample marked "quartz, cleaned." The results were practically identical. Another sample of inferior manufacture gave, under the same conditions, the same results as given by the curve marked "fused quartz." 


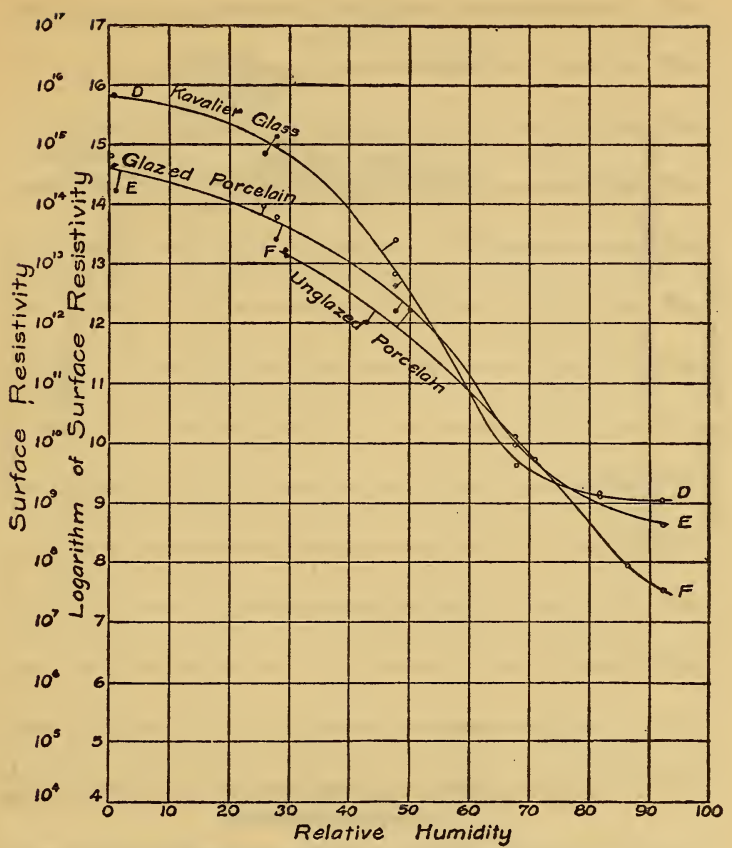

FIG. 13.-Change of surface resistivity with humidity of glass and porcelain

The curves for three kinds of glass are given in Figs. I2 $_{2}$ and $\mathrm{r}_{3}$. The Kavalier glass is a very hard combustion tubing having a large potassium and calcium content and a small amount of sodium. The German glass is a soft glass tubing such as is usually used in glass blowing. The plate glass was a piece from a plate-glass window. It will be noticed that the curves fall very sharply at about $3 \circ$ per cent humidity, and that above 70 per cent humidity the change is not so marked. These samples were tested twice with the results as given. Later they were cleaned with chromic acid in the manner described for quartz and the resistances measured a third time. While the results did not show such marked changes as in the case of quartz, they were all in the same direction. Also the effect was most pronounced on the hard Kavalier glass and least so on the plate glass. It is known that the Kavalier glass is less soluble ${ }^{7}$ than the other forms. Hence it is quite probable that the difference may largely be due to the difference in the conductivity of the water solution on the surface.

In Fig. I3 are also given curves for glazed and unglazed porcelain. The glazed porcelain was the base of a small porcelain switch, while the unglazed was a plate such as is used in chemical work. 


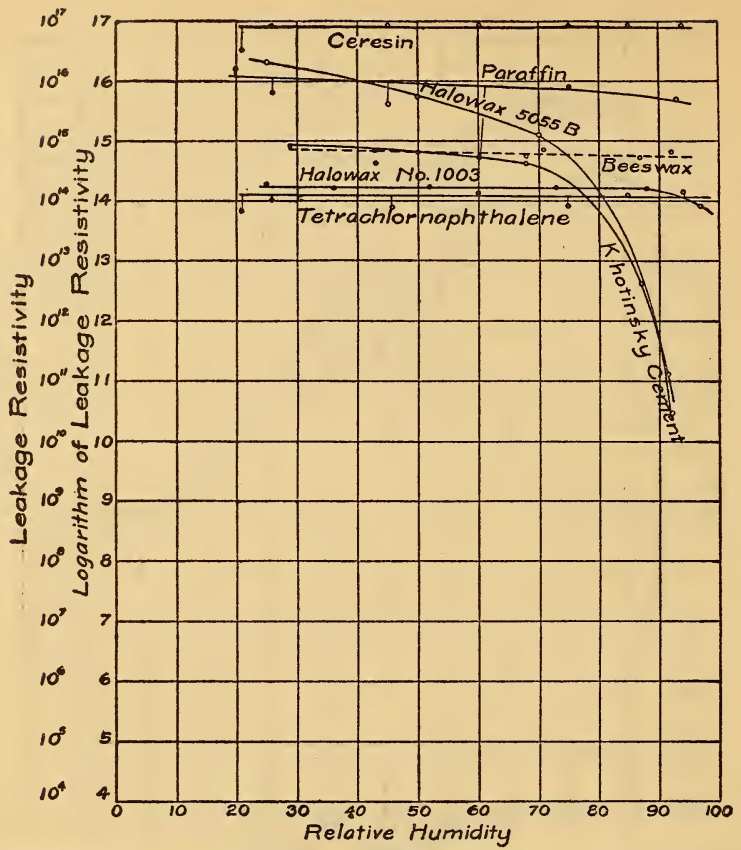

FIG. I4.-Change of leakage resistivity with humidity of waxes

In Fig. I4 are given curves for various waxy materials. It has been found impracticable to determine the surface resistivity of the most of these materials, so the results are given in terms of the leakage resistivity. Ceresin is refined from the mineral ozokerite. It somewhat resembles paraffin, but has a higher melting point $\left(69^{\circ}\right)$. An attempt was made to measure the leakage resistance of a sample at several humidities by the galvanometer method using a distance of $\mathrm{I} \mathrm{mm}$ between the plates. It was impossible to obtain a readable deflection, but it is certain the values are above those given in the curve. With the electrometer method the surface resistivity was still too high to measure, certainly above $10^{18} \mathrm{ohms.} \mathrm{A} \mathrm{special} \mathrm{paraffin} \mathrm{having} \mathrm{a} \mathrm{melting}$ point of $58^{\circ} \mathrm{C}$. also gave results too high to measure by any method at our disposal. A commercial form of paraffin known as parowax (melting point $5^{\circ}$ ) gave the results shown in the curve. Measurements by the electrometer method gave a satisfactory check on these results.

The curve for beeswax was obtained from a sample of the yellow, unrefined material. White beeswax gave results which are almost identical. For these materials the surface must be fresh. They deteriorate quite rapidly when exposed to light and moisture.

The sample of tetrachlornaphthalene was furnished by Dr. Baekeland. It is doubtless a mixture of several isomers and may contain other chlorinated naphthalenes. It 


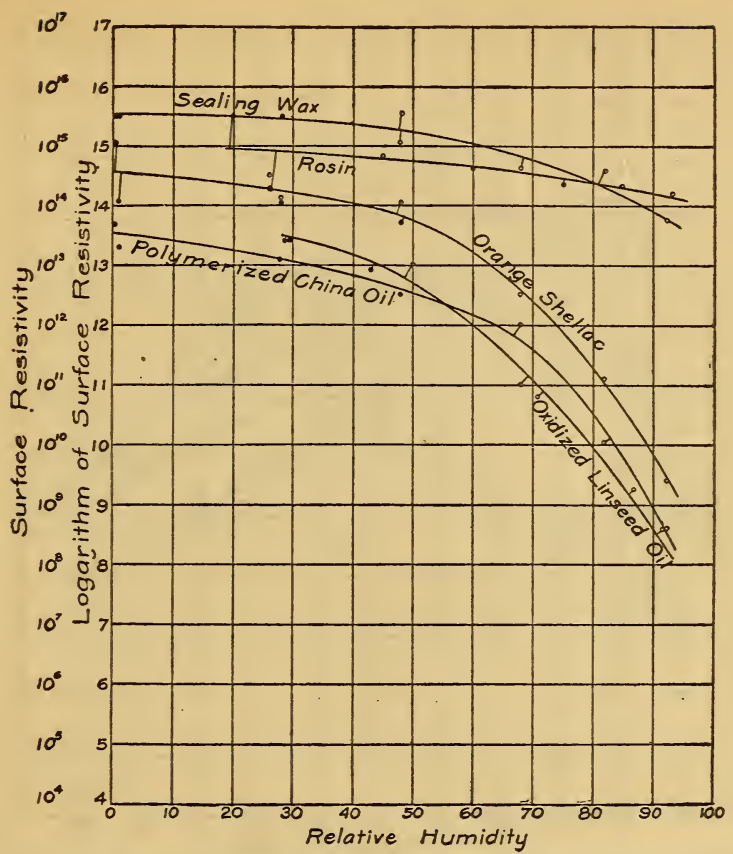

FIG. I5.-Change of surface resistivity with humidity of varnish materials

is about the consistency and color of yellow beeswax and has a very characteristic odor. The samples of "halowax" were furnished by the Condensite Co. of America. They are chlorinated naphthalenes. The sample No. 1003 is largely tetrachlornaphthalene. It is of a gray color, but in other respects has much the same properties, including odor, as the sample furnished by Dr. Baekeland. The sample ${ }_{50}{ }_{55} \mathrm{~B}$ is a higher chlorinated naphthalene, being largely hexachlornaphthalene.

The Khotinsky cement was flowed on a glass plate. The thickness was such that no appreciable part of the current flowed through the glass.

These waxy materials show the least change with humidity of any of the substances tested. This is doubtless due to the fact that the water does not wet the surface, hence instead of spreading over the surface is collected in minute drops.

In Fig. I5 are materials used in making varnish. The rosin is common rosin or colophony. It was melted and cast into a thick cake. The shellac, China oil, and linseed oil were applied to glass plates, several coats being used to obtain a sufficient thickness. The test upon a sample of white shellac gave results somewhat lower than for orange shellac. This was doubtless accounted for by the fact that the white shellac was not as thoroughly dried as the orange shellac.

The sealing wax was a stick of "treasury" wax. It consists largely of rosin, shellac, and coloring matter. It is of interest that the curve follows rosin more closely than shellac. 


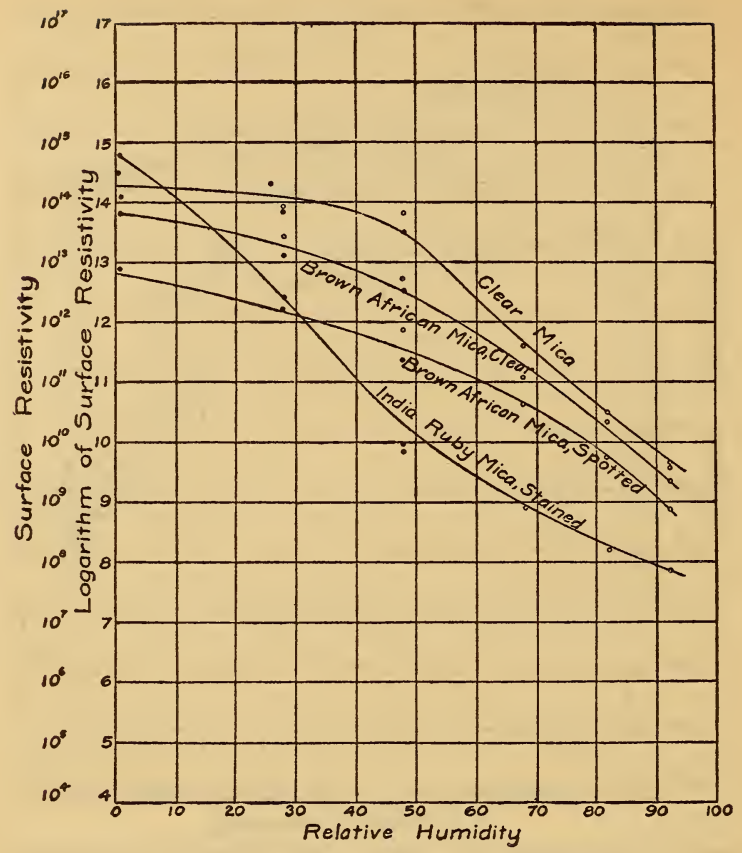

Fig. I6.-Change of surface resistivity with humidity of micas

In Fig. I6 are given the results upon samples of mica. The clear mica was entirely colorless. It was taken from a mica condenser. The surface was cleaned with gasoline, but it was not subjected to any treatment which would remove the last traces of paraffin and grease. Other samples were furnished by Meirowsky Bros., of New York, and the designations are those given by them. These designations indicate the color and source of the sample.

Another sample of India ruby mica was tested, which gave a curve nearly coinciding with the brown African mica, clear. These results are mainly interesting on account of the variability which is found in this material. It is evident that it would require an extended investigation to determine the relative merits of the different varieties of mica. 


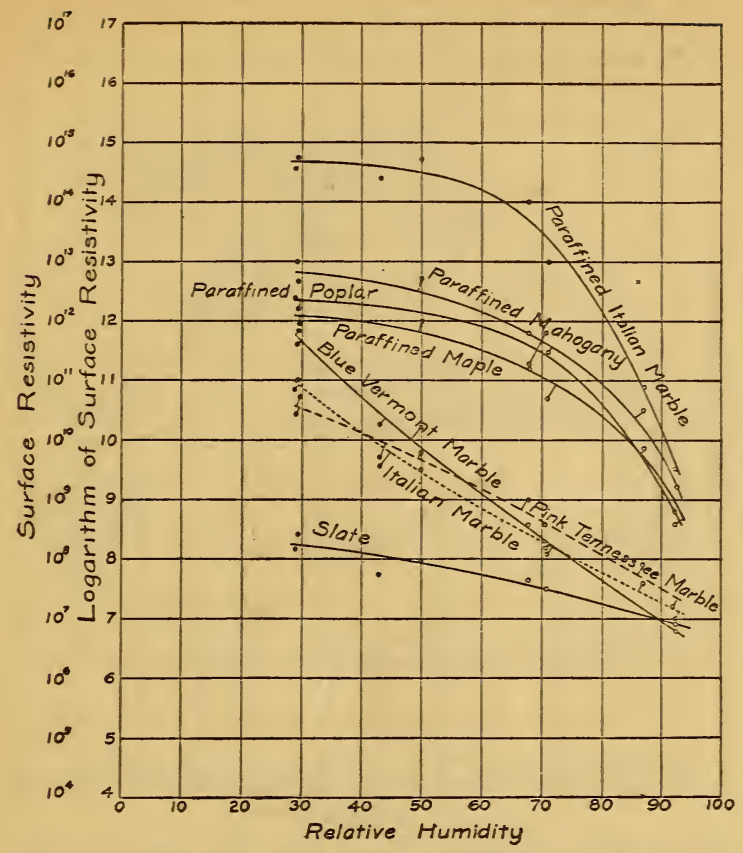

FIG. I7.-Change of surface resistivity with humidity of marble and paraffined woods

In Fig. I 7 are grouped the curves of some of the poorer insulators, together with some curves showing the effect of impregnating them with paraffin. The slate was taken from the base of a switch and its origin is not known. The source of the marbles is stated on the curves. All were free from metallic veins, and were the equal of any that are used in switchboard construction. It appears that the coloring material in the Vermont and Tennessee marbles have very little effect on the surface leakage.

The marble and the different varieties of wood were impregnated with paraffin by keeping them in molten paraffin until no more air bubbles were given off. After cooling, the wood was planed and the marble sandpapered so that the resistance was measured over a surface of wood or marble with paraffin filling the pores and not over a layer of paraffin on the surface. The woods of more open grain such as mahogany and poplar show a somewhat higher insulation than the closer grained maple.

The paraffined marble shows the considerable increase in the insulation that may be obtained by impregnating with paraffin. The surface does not present as clear and pleasing appearance as before paraffining, and it accumulates dust more readily. The marked decrease of the resistance with increasing humidity is not readily explained. One would expect that it would behave more like paraffin which shows little change. 


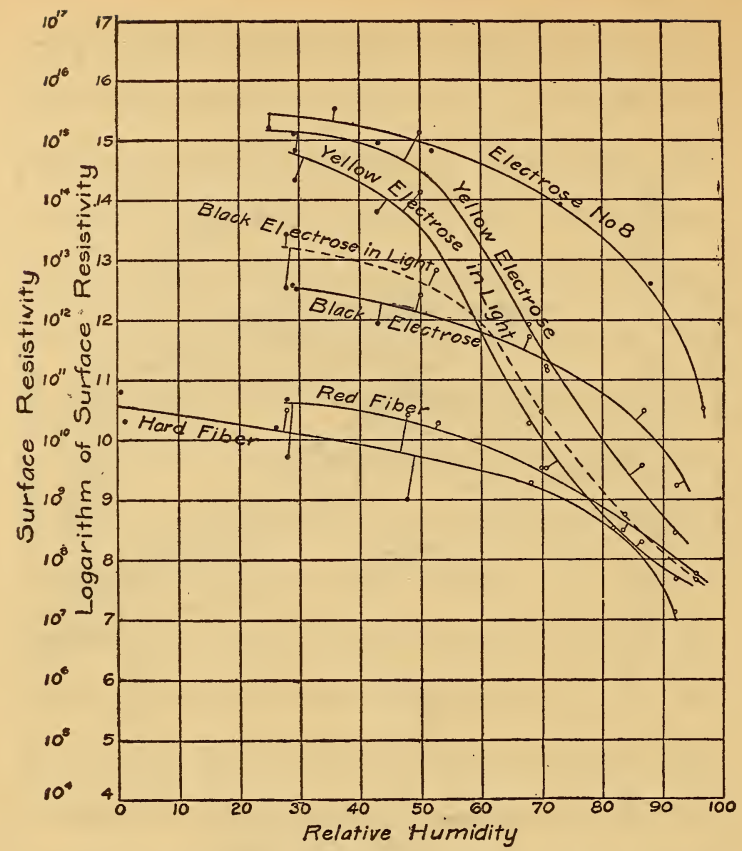

FIG. 18.-Change of surface resistivity with humidity of electrose and fiber

Beginning with Fig. 18 are given the results upon a number of materials which are manufactured under trade names. There are many materials in chis class upon which results are not given, but the aim has been to include the most of the representative ones. For example, there are many firms making various bakelite compositions, many of them being sold under names which do not suggest their composition. Yet the values given under bakelite cover sufficiently well these materials.

The samples given in Fig. I8 are various varieties of electrose, together with red fiber and hard fiber. Hard fiber is made by treating a soft cotton paper with chloride of zinc. This reduces the paper to a jelly. The excess of zinc chloride is dissolved in water, after which the material is dried, pressed, and rolled.

The electrose samples were obtained from the Electrose Manufacturing Co., of Brooklyn. Two samples of two different kinds (black and yellow) were obtained several years ago. One sample of each kind was exposed to the light, while the other sample was kept in the dark. The results after exposing for three years are given in the curves. It will be noted that at low humidities the resistance of the sample of black electrose is higher after exposure to the light than before. This is doubtless due to the formation of fine cracks on the surface, which increase the leakage path at low humidities, but which are bridged by small drops of water at the high humidities. In general the deterioration has been slight. Electrose No. 8 is a more recent product, being one of several very similar samples which were submitted. 


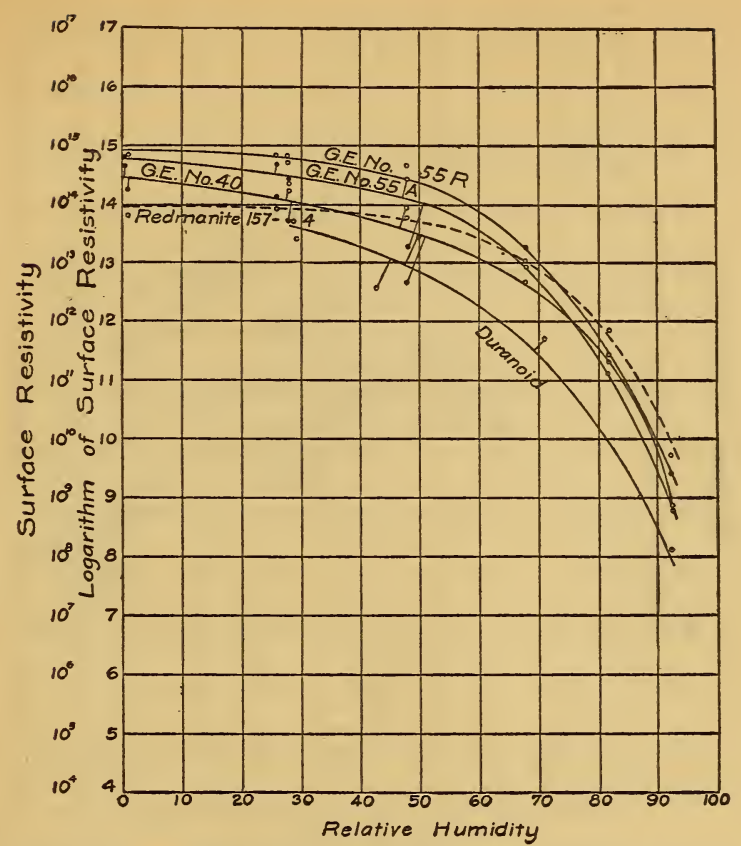

FIG. I9.-Change of surface resistivity with humidity of miscellaneous molding compounds

In Fig. I9 are shown the curves for duranoid, redmanite ${ }_{57-4}$, and three materials submitted by the General Electric Co. The duranoid is from the Duranoid Manufacturing Co., of Newark, N. J. It closely resembles hard rubber in external appearance.

The samples G. E. $40,55 \mathrm{~A}$, and $55 \mathrm{R}$ have also an appearance very much like hard rubber. They were exposed to the sunlight for four months without any effect that could be detected.

The sample of redmanite $157^{-4}$ was one of several samples submitted by Dr. Redman, of the University of Kansas. All have an amber-like appearance, though the color varies considerably. There was considerable variation in the surface resistivity, the one whose curve is given being among the best. 


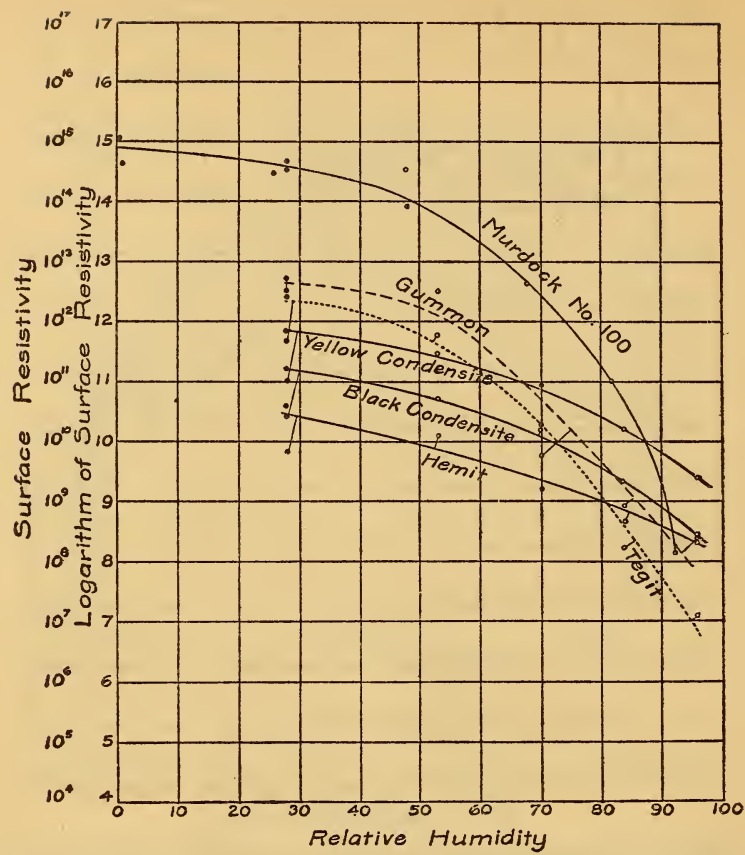

FIG. 20.-Change of surface resistivity with humidity of miscellaneous molding compounds

The samples in Fig. 20 are commercial insulators. The curve marked Murdock No. Ioo is representative of several samples furnished by the J. W. Murdock Co., of Chelsea, Mass. The other samples gave curves which lie very close to the curve that is given. This is of considerable interest, since they are quite different in external appearance. However, they were all made either with shellac as a binder or with shellac mixed with some gum. A comparison of this curve with that of orange shellac given in Fig. I5 shows that they are almost identical. It would therefore appear that in certain cases the shellac forms the surface layer. In this connection it should be noted again that in the case of sealing wax, which is a mixture of shellac and rosin, the curve follows that of rosin more closely than shellac.

The gummon, tegit, and hemit are from the Hemming Manufacturing Co., of Garfield, N. J. They are coal-tar products.

The black and yellow condensite are from the Condensite Co. of America, Glen Ridge, N. J. They are phenol-condensation products combined with binders. It would appear in this case that the presence of the black coloring matter affects the surface resistivity. 


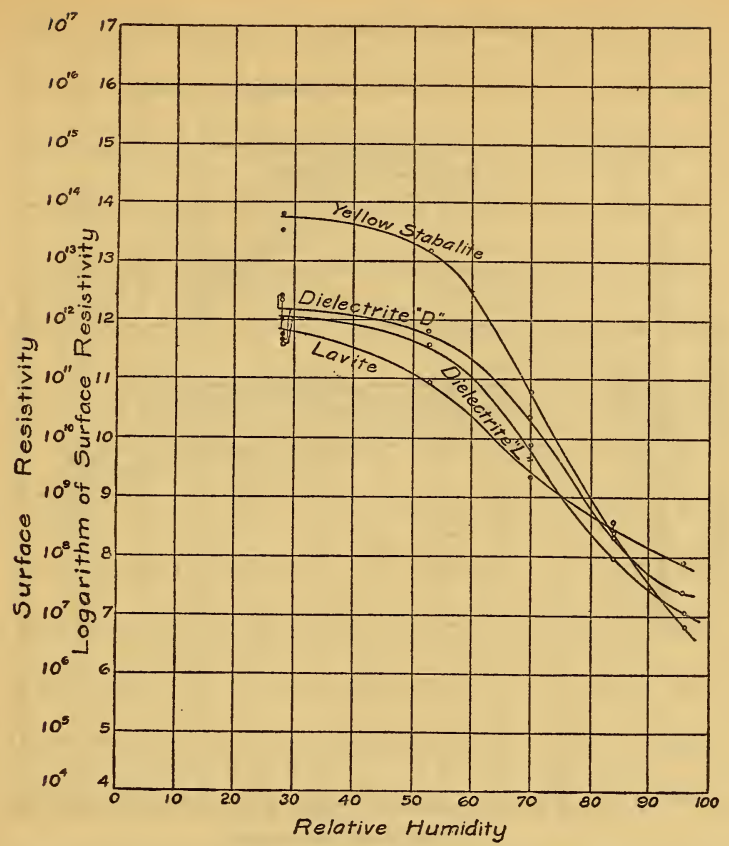

FIG. 2I.-Change of surface resistivity with humidity of miscellaneous materials

In Fig. $2 \mathrm{I}$ are the curves for some miscellaneous materials. Stabalite is a rubber compound which is used to a considerable extent in Germany, but which has not found extensive use in the United States. It is manufactured by the Algemein Elektricitäts Gesellschaft, of Berlin, Germany. The samples of dielectrite were furnished by the Staunton Dielectrite Rubber Co., of Muskegon, Mich. The curves are given for two samples as showing what reproducibility may be expected between two samples of the same material. This was chosen as representing the difference that may be expected in samples which are of the same manufacture. These samples were not from the same piece, but were made at the same time in the same mold. Material made at different times according to the same method may have a somewhat larger difference. The results on the large number of insulators measured lead to the conclusion that the difference in the surface resistances of two samples of the same material at any humidity seldom varies by as much as a factor of ro.

The sample of lavite was furnished by the D. M. Steward Manufacturing Co., of Chattanooga, Tenn. It somewhat resembles unglazed porcelain. It is familiar to many from its extensive use in the tips of gas burners. The curve also resembles that of unglazed porcelain. 


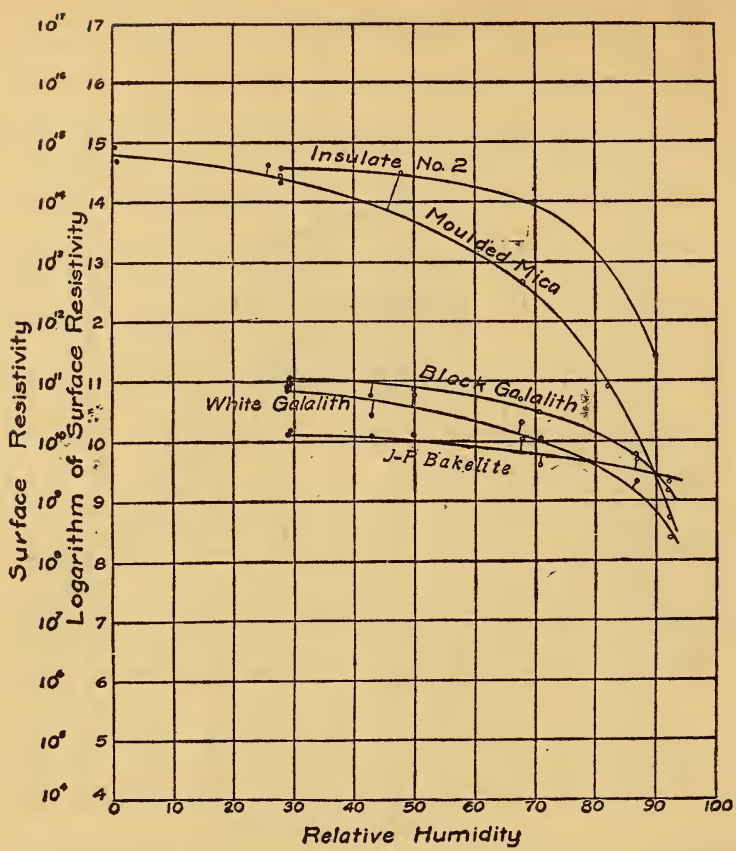

FIG. 22.-Change of surface resistivity with humidity of miscellaneous materials

In Fig. 22 are the curves of some miscellaneous materials. Insulate No. 2 is representative of several samples, all having nearly the same surface resistivity, which were furnished by the General Insulate Co., of New York. It is a moulding material, certain grades of which closely resemble hard rubber. Moulded mica and J-P Bakelite are also moulding materials, manufactured by the Johns-Pratt Co., Hartford, Conn. The moulded mica consists of ground mica and asbestos with shellac as a binder. It should be noted that, as in the case of the Murdock compounds, this curve corresponds very closely with the curve for shellac, showing that so far as surface effects are concerned they are almost entirely dependent upon the shellac. The sample was also exposed to sunlight for a period of four months without appreciable deterioration. The J-P Bakelite is a bakelite compound.

The samples of galalith were obtained from the International Galalith Gesellschaft, having factories in England, France, and Germany. The material is made from the casein of milk, and uncolored is being used as a substitute for ivory. For insulating purposes it is somewhat better than ivory. In this case the introduction of coloring matter evidently improves the surface leakage. 


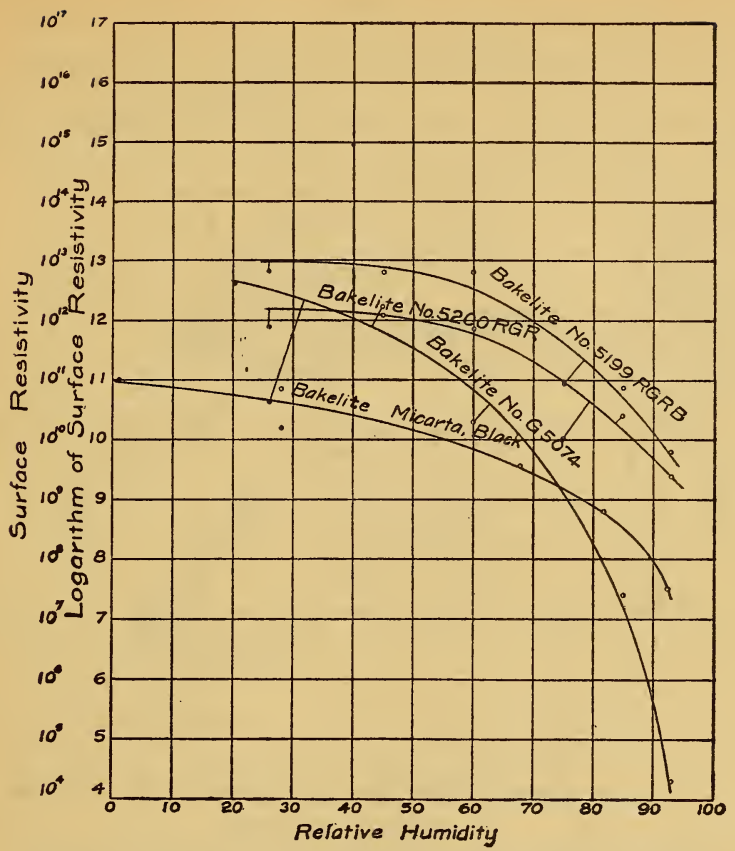

FIG. 23. - Change of surface resistivity with humidity of bakelite

In Figs. 23 and 24 are shown the curves for various samples of bakelite. The bakelite micarta was secured from the Westinghouse Electric \& Manufacturing Co., of Pittsburgh. The other samples were furnished by Dr. Baekeland, of the General Bakelite Co., New York City. They furnish an interesting study of the effect of adding substances, portions of which may dissolve in the insulator.

The bakelite micarta is made in much the same manner as is indicated below for sample No. I. It will be observed that the curves for these two materials have the same general form.

The curve of Fig. 24 for bakelite $\mathrm{L}_{55} 8$ shows a sample which has recently been produced by Dr. Baekeland and which he believes to be very pure bakelite, starting from phenol as a base. Its insulating properties are very.good, and it shows relatively little change with humidity. The curve for bakelite, regular, is also for bakelite without a filling material. It was, however, made from cresol and ammonia was used as a catalylic agent. This shows how slight variations in composition may produce very pronounced effects in the surface resistivity. The composition and method of preparing the other samples is given in Table 4, page 399 , which was furnished by Dr. Baekeland. 


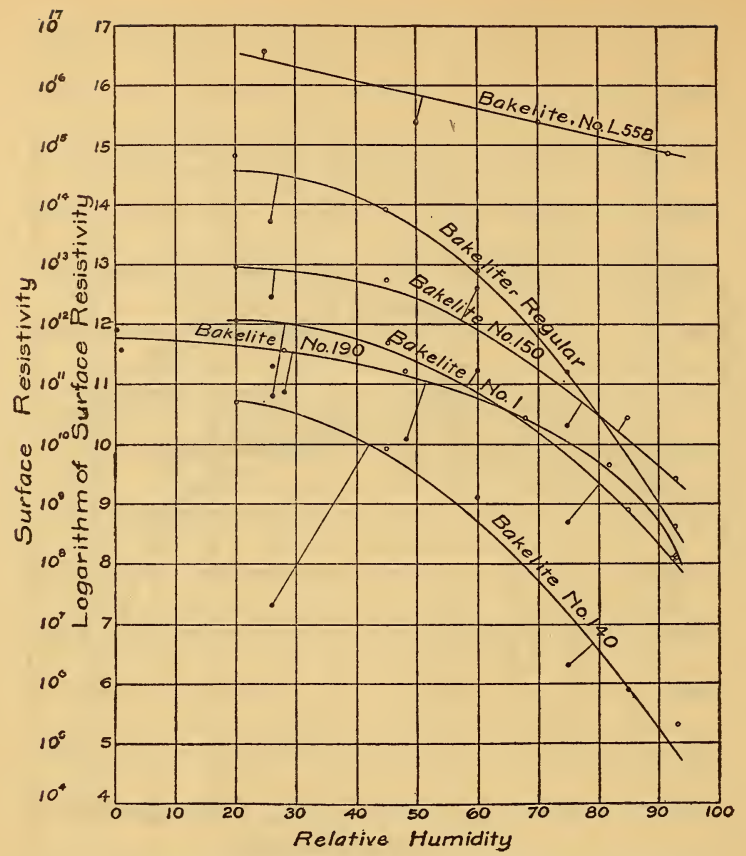

FIG. 24.-Change of surface resistivity with humidity of bakelite

In the curves for $I_{40}$ and $I_{50}$ is shown the effect of the catalytic or condensing agent. The curve of No. I40, in which caustic soda is the catalytic agent, lies below that of No. $1_{50}$, in which ammonia is used as a catalytic agent. Evidently sufficient sodium salts remain on or near the surface to materially effect the condensation of water, and also the volume resistivity of the material is lowered by their presence. No. G. 5074 also contains sodium salts and, in addition, talcum as a binder. It shows very pronounced effects due to humidity. That water even penetrates into the material is shown by the curve of Fig. 5. No. Igo is similar to $15^{\circ}$, except that cresol is used as a base. No. ${ }^{1} 99$ R. G. R. B. is the same as No. ${ }_{5} \circ$, but it was prepared with special care. There is but little difference between the curves of the two. No. $5^{200}$ R. G. R. is the same as No. $5_{50}^{\circ}$ except that some china clay is used as a binder. The curves show that this has a deleterious effect.

From the above, certain conclusions can be reached. In the first place, the catalytic agent apparently has a marked influence on the final product. Also the nature of the binding material influences the surface resistivity. This is in contrast with the effect which was observed in the case of shellac. 
TABLE 4

Table Showing the Composition of the Different Samples of Bakelite

\begin{tabular}{|c|c|c|c|c|c|}
\hline $\begin{array}{l}\text { Sample } \\
\text { number }\end{array}$ & $\begin{array}{l}\text { Per cent } \\
\text { bakelite }\end{array}$ & Filling material & Phenolic body & $\begin{array}{l}\text { Condensing } \\
\text { agent }\end{array}$ & $\begin{array}{l}\text { Meihod of preparing } \\
\text { sample }\end{array}$ \\
\hline $1 \ldots \ldots .$. & $?$ & Paper.............. & $\begin{array}{l}\text { Mixture of ortho- } \\
\text { cresols, meta- } \\
\text { cresols, and } \\
\text { paracresols. }\end{array}$ & Ammoria ..... & $\begin{array}{l}\text { A composite cardboard } \\
\text { impregnated homo- } \\
\text { geneously with ba- } \\
\text { kelite varnish and } \\
\text { hardened in the hot } \\
\text { hydraulic press. }\end{array}$ \\
\hline $140 .$. & 50 & Vegetable fiber.... & Phezol $\left(\mathrm{C}_{6} \mathrm{H}_{5} \mathrm{OH}\right)$. & Caustic soda.. & $\begin{array}{l}\text { Moulded in hot hy- } \\
\text { draulic press } 160^{\circ}- \\
180^{\circ} \mathrm{C} \text {. }\end{array}$ \\
\hline $150 \ldots$ & 50 & ......do.. & ....do.............. & Ammoria..... & Do. \\
\hline $190 \ldots \ldots \ldots \ldots$ & 50 & ..... do... & $\begin{array}{l}\text { Misture of ortho- } \\
\text { cresols, meta- } \\
\text { cresols, and } \\
\text { paracresols, and } \\
\text { cyclic hydrocar- } \\
\text { bons. }\end{array}$ & .....do......... & Do. \\
\hline 5199 R. G. R.. & 50 & ......do..... & Phenol $\left(\mathrm{C}_{6} \mathrm{H}_{5} \mathrm{OH}\right)$. & .....do............ & Do. \\
\hline 5200 R. G. R.. & 50 & $\begin{array}{l}\text { Misture of vege- } \\
\text { table fiber and } \\
\text { china clay. }\end{array}$ & .....do................ & & Do. \\
\hline G. $5074 \ldots \ldots$. & 35 & Talcum ..... & ......do.. & Caustic soda.. & Do. \\
\hline
\end{tabular}

\section{EFFECT OF TEMPERATURE}

The effect of change of temperature on the surface resistivity was investigated for a number of samples. From the preceding work it is apparent that the humidity must be maintained constant. From the work of Regnault it is found that the relative humidity of air in equilibrium with a sulphuric acid solution is almost independent of the temperature. Hence, it was only necessary to set the thermostat for a different temperature, since the change in the amount of moisture in the air necessary to maintain the relative humidity constant is automatically taken care of by the sulphuric acid solution.

The first attempt was made at a humidity of 25 per cent by changing the temperature from $25^{\circ}$ to $30^{\circ} \mathrm{C}$. From these measurements no change in the surface resistance with temperature was detected. However, at this humidity the current which flows through the volume of the dielectric is so large a part of the total 
that determinations of the surface resistance are very inaccurate. The leakage resistance decreased in all cases, but in no case by more than a factor of two. This change is entirely accounted for by the change in the volume resistivity with temperature, data for which has already been given.

In order to obtain more accurate results upon the effect of temperature on the surface resistivity, samples were measured at $25^{\circ} \mathrm{C}$ and 94 per cent humidity, then the temperature increased to $3 \mathrm{I}^{\circ} \mathrm{C}$, keeping the humidity constant. A range of samples was chosen from very good insulators to poor insulators. In no case did the resistance vary by more than a factor of three, and in most cases it was much less. In some cases there was an increase in resistance, in others a decrease.

Hence, for practical work in the laboratory changes in surface leakage due to changes in temperature are of so little importance compared to the changes in resistance due to changes in relative humidity that they may be neglected. It is not to be supposed that this will hold for temperatures considerably removed from those used in this investigation.

\section{EFFECT OF EXPOSURE TO LIGHT}

Exposure to light may produce either a temporary or permanent effect. The temporary effect causes a change in surface leakage only while the light is shining on the surface. This was observed by Goldmann and Kalandyk ${ }^{8}$ in the case of sulphur and by Bates ${ }^{9}$ in the case of sulphur and ebonite. These results could not be reproduced in this laboratory.

Exposure to light may produce a chemical change at or near the surface which will be permanent. This chemical change may change the appearance of the material as well as the surface resistivity. However, there does not appear to be any connection between the two. Some samples, which show a very pronounced change in appearance, show very little change in surface resistivity and the reverse is sometimes the case.

The work under this head may be divided into two parts; (a) the effect of exposure to sunlight, and $(b)$ the effect of exposure to

\footnotetext{
${ }^{8}$ Ann. d. Phys. (4), 36, p. 589; r9rr.

9 British Ass. Adv. Sci., 1909, p. 405, and by Le Radium, 8, p. 312; Igrr.
} 
ultra-violet light. The chemical changes produced by sunlight are usually much slower than those produced by ultra-violet light. Hence, it was possible to obtain effects in a few hours by means of ultra-violet light which would require months or even years to produce by sunlight. It must, however, be borne in mind that the results may not, in all cases, be identical. Hence, while the results found with ultra-violet light are valuable as indicating the chemical stability of the insulator, yet it is to be expected that in some cases the same changes will not take place in sunlight.

\section{(a) EFFECT OF SUNLIGHT}

As the chemical changes produced by sunlight take place very slowly, the number of specimens examined has been limited. The major portion of the work has been done upon hard rubber where the changes take place rather rapidly, though some work has been done upon more resistant materials.

(1) Deterioration of Hard Rubber.-For some years a study has been made of the effect of sunlight upon hard rubber. In Fig. 25 is a curve showing the deterioration with time of a sample of hard rubber exposed to sunlight. As the effect of humidity was not appreciated at the time the work was begun, the results must be considered qualitative rather than quantitative. However, as the measurements were always made at humidities less than 50 per cent, as simultaneous measurements upon a similar sample which had been kept in the dark never showed marked changes, and as two other samples from different sources gave similar results, it is improbable that a more careful study would yield results of great importance.

It will be noticed that the sample was prepared in January, 1907, and exposed to the diffuse light of the laboratory for nearly a year, when measurements were taken and marked deterioration noted. The sample was then exposed to sunlight, being placed vertically just inside a south window. In July, 1908, the resistance was very low and it was decided to see if the sample could be restored to its original condition by cleaning. That this was accomplished is shown by the measurements of December, I908, when the resistance was somewhat higher than it was when the 
sample was new. The method of cleaning is given in the following section.

The sample was then placed in the sun, and subsequent measurements showed that it decreased in resistance, but at a somewhat slower rate than in the previous case. This is in agreement with the results of Rayner. ${ }^{10}$

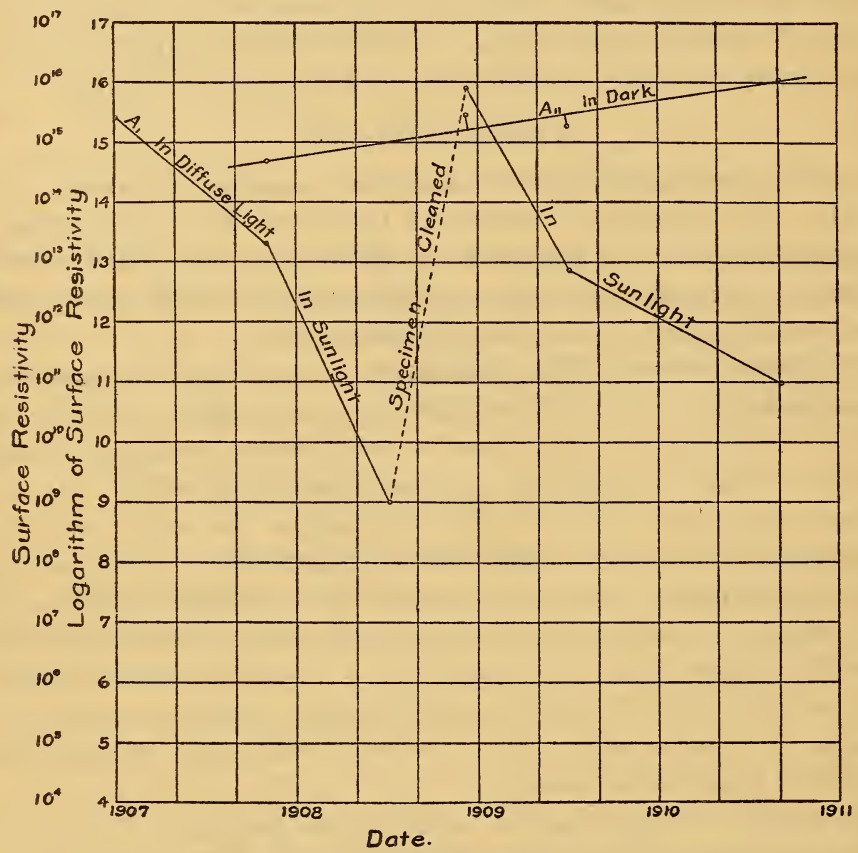

FIG. 25.-Deterioration of hard rubber by exposure to sunlight

The curves for the change of resistance of this sample with humidity taken after its removal from the sunlight in 1909 is given in Fig. Io (American hard rubber in light). It shows very pronounced changes with humidity.

The cause of these changes is evidently in the chemical decomposition of the hard rubber by light. Hard rubber is formed by 
vulcanizing Para rubber and sulphur, using about two-thirds rubber and one-third sulphur. There is also incorporated a large per cent of mineral filling material. When this rubber is exposed to light in the presence of air, complicated chemical reactions are set up which result in oxidizing the sulphur to the equivalent of sulphuric acid. This may take up ammonia from the air to form ammonia sulphate, or it may attack the filling material, forming sulphates of various kinds. Many of these sulphates are very hygroscopic, condensing water from the air to form a layer on the surface which is highly conducting due to the dissolved salts. Hence, the presence of these sulphates increases the amount of moisture and also increases its conductivity, so that the large decrease in resistance is readily explained.

(2) Renovation of the surface of Hard Rubber.-In view of the above considerations it is evident that if the sulphates are removed, the rubber should be restored to its original resistivity. However, several methods of cleaning were tried upon the samples above described before a satisfactory one was discovered. Rubbing with oil improved the insulation, but did not restore it to its original value. Cleaning with sodium hydroxide improved the appearance but not the insulation. Finally the samples were suspended in a vessel of distilled water and allowed to remain for two days. The results are shown in the measurements of December, r9o8. It will be noticed that the resistance is somewhat higher than the original value. This is due to the fact that the surface has been somewhat roughened, thus making a longer leakage path.

In some later work it was found advisable to first wash the surface in a dilute solution of ammonia, then to wash it thoroughly with water. The surface should be wiped with a cloth until it is dry, then rubbed with a cloth moistened with light lubricating oil. The essential factor in improving the insulation is water, the other processes being used to improve the appearance of the sample.

(3) Deterioration of Other Materials.-In Fig. I8 are given results upon two samples of electrose which had been exposed to sunlight for more than two and a half years. The changes which took place were not very marked and appeared to be more physical than chemical. The surface of the black electrose after long exposure showed fine cracks, which doubtless explains the increase 
in resistance of that specimen for low humidities. Both specimens showed slight discoloration, but there was no formation of salts on the surface as in the case of hard rubber.

Samples of moulded mica (this uses shellac as a binder, and its surface properties are almost identical with shellac) and of moulding compositions $55 \mathrm{~A}, 55 \mathrm{R}$, and 40 furnished by the General Electric Co., were exposed to sunlight for four months in the winter of I9I 2 and r9r3. The curves after exposure were identical with those before exposure.

\section{(b) EFFECT OF EXPOSURE TO ULTRA-VIOLET LIGHT}

The effect of ultra-violet light in accelerating chemical action is well known. As the effect of light upon the surface resistivity is largely due to chemical action upon the surface layers, it seemed probable that those samples which deteriorate in sunlight would deteriorate much more rapidly in ultra-violet light. As this test could be applied in much less time than the test with sunlight, it seemed desirable to try it upon a number of samples.

The source of ultra-violet light was a quartz mercury vapor lamp taking 4 amperes on I 8 volts. The specimens were placed about I 2 inches below this lamp and exposed to the radiation for 19 or 20 hours. All the materials showed some change in appearance, except in the case of some samples of glass. The effect upon the surface resistivity was very different with different materials. Results upon six representative samples are given in the curves of Figs. 26 to 28 . To make comparison easier, curves for the samples in their normal state are here given, and the curves obtained after exposure to ultra-violet light are plotted on the same sheets.

In Fig. 26 are given curves for hard rubber and for a specimen of hard rubber coated with bakelite. In both cases there was an interval of but one day between finishing the first curve and beginning the second. In that interval they were exposed to ultraviolet light for about 20 hours. The hard rubber has deteriorated as much as after several months exposure to strong sunlight.

The curves for the sample of hard rubber covered with bakelite are very interesting. The hard rubber was cut from the same piece as the sample mentioned above. It was covered with a thin coating of bakelite by Dr. Baekeland. Bakelite lacquer was 
applied by spraying, then the sample air-dryed, and finally baked for 12 hours at $120^{\circ} \mathrm{C}$. The curves show that there was a decided improvement in the surface insulation ${ }^{11}$ due to the thin coat of bakelite, especially at the higher humidities. However, when the sample had been exposed to ultra-violet light for 20 hours, the surface resistivity at the higher humidities was less than one-ten

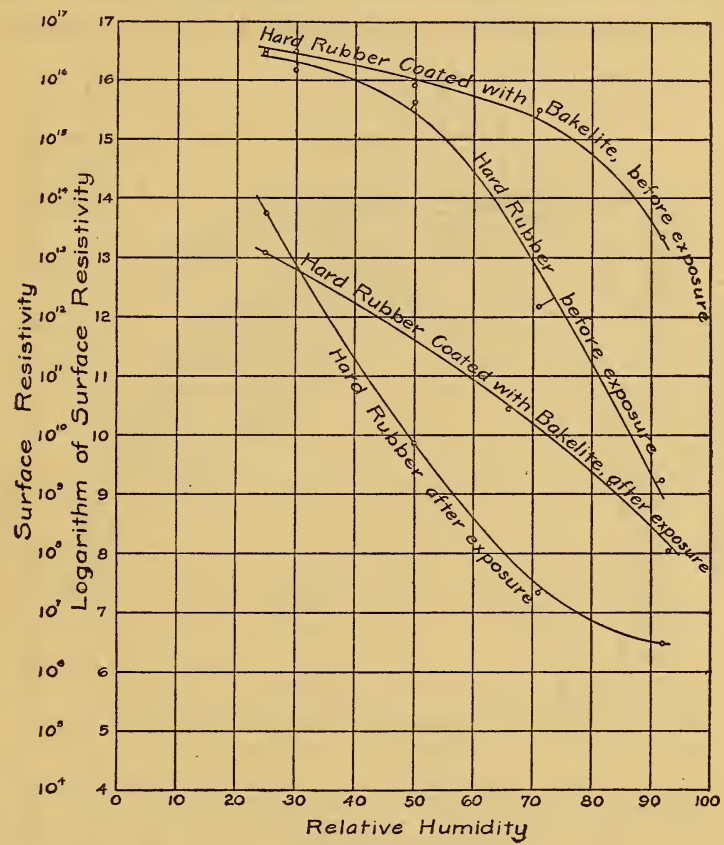

FIG. 26.-Change of surface resistivity with humidity of hard rubber and hard rubber coated with bakelite both before and after a 2o-hour exposure to ultra-violet light

thousandths of the value before exposure. The relative decrease was somewhat larger than for the hard rubber. The exposed surface of the bakelite covered sample appeared but little different to the naked eye than the unexposed surface, but under a microscope the exposed surface appeared covered with innumerable

11 This was observed by Wommeldorf, who uses this material in constructing a new type of electrostatic machine. See Electrotech Zs., 35, p. 6r; r9r4. 
very fine blisters. Whether a like effect would take place if the sample was exposed to sunlight can be ascertained only by experiment. Such experiments are now in progress.

In Fig. 27 are results upon glyptol and moulded mica. The curves showing the surface resistivity before exposure to ultraviolet light are the same as those previously given. The other curves were after exposure to ultra-violet light for 20 hours. The

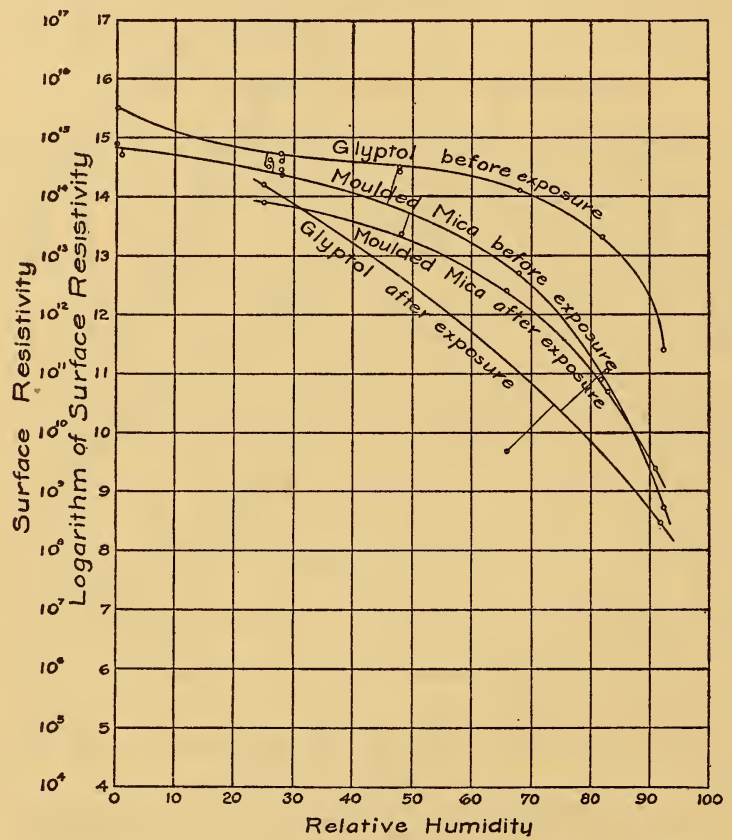

Fig. 27.-Change of surface resistivity with humidity of glyptol and moulded mica both before and after a 20-hour exposure to ultra-violet light

difference in the case of moulded mica (a compound using shellac as a binder) is small; and since the curves are not for the same sample, it is quite possible that no change whatever has taken place.

In the case of glyptol, however, the change is very marked. Since glyptol is a synthetic compound which has the appearance 
and many of the properties of amber, it seemed possible that amber itself would be affected by ultra-violet light. Experiment showed that this is the case, though it was not so pronounced as in the case of glyptol.

In Fig. 28 are shown the results upon bakelite and electrose. The electrose is not the same as that whose curves showing the

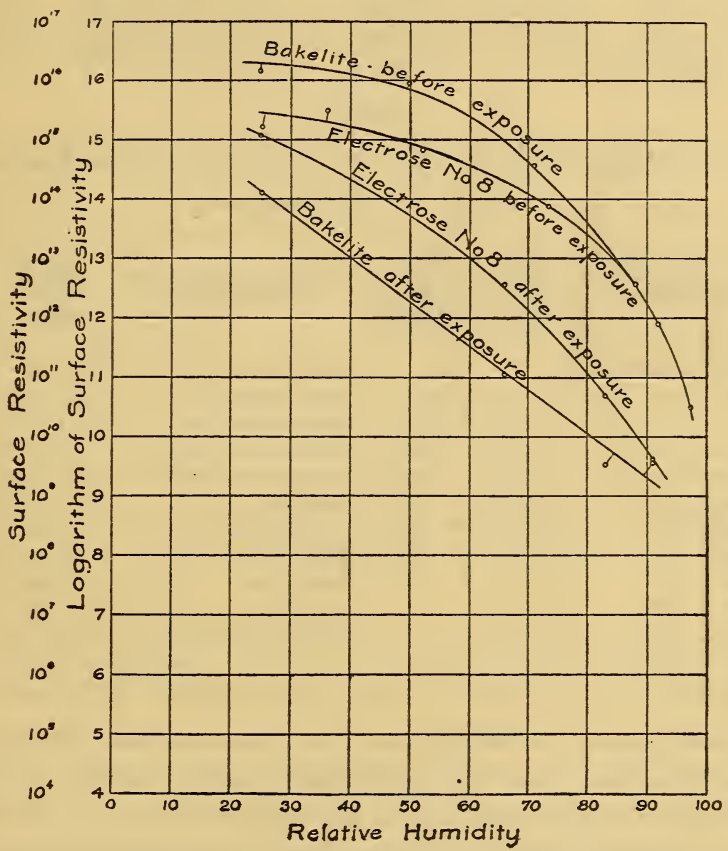

FIG. 28.-Change of surface resistivity with humidity of bakelite and electrose both before and after 20 hours' exposure to ultra-violet light

effect of sunlight are given in Fig. 18, though it is doubtless similar. The deterioration for 20 hours in ultra-violet light is as great as in sunlight for several years. The curves of bakelite are those of a single sample. It had very high surface resistivity before exposure to ultra-violet light, being among the best samples furnished by Dr. Baekeland. There was an appreciable deterioration due to the exposure to ultra-violet light. 
Besides the materials quoted above, a number of other samples were studied. No attempt was made to examine all the samples. To give an idea of the changes which take place, Table 5 was prepared. In the second column of this table are given values of the surface resistivity measured at 90 per cent humidity after exposure to ultra-violet light for 20 hours. In the third column are given the values of the factor by which the surface resistivity after exposure must be multiplied to give the surface resistivity before exposure.

TABLE 5

Effect of 20 Hours Exposure to Ultra-violet Light upon Surface Resistance

[Temperature, $25^{\circ} \mathrm{C}$; humidity, 90 per cent]

\begin{tabular}{|c|c|c|c|c|c|}
\hline $\begin{array}{l}\text { Materials which showed } \\
\text { pronounced decreases }\end{array}$ & $\begin{array}{l}\text { Surface } \\
\text { resistivity } \\
\text { after } \\
\text { exposure }\end{array}$ & $\begin{array}{l}\text { Factor } \\
\text { by which } \\
\text { resistance } \\
\text { decreased }\end{array}$ & $\begin{array}{l}\text { Materials which showed } \\
\text { slight changes }\end{array}$ & $\begin{array}{l}\text { Surface } \\
\text { resistivity } \\
\text { after } \\
\text { exposure }\end{array}$ & $\begin{array}{c}\text { Factor } \\
\text { by which } \\
\text { resistance } \\
\text { decreased }\end{array}$ \\
\hline $\begin{array}{r}\text { Hard rubber covered with } \\
\text { bakelite } * . . \ldots \ldots \ldots \ldots \ldots\end{array}$ & $4.6 \times 10^{8}$ & 48000 & $\begin{array}{l}\text { Moulded mica............. } \\
\text { White celluloid ........... }\end{array}$ & $\begin{array}{l}1.4 \times 10^{9} \\
9.1 \times 10^{8}\end{array}$ & $\begin{array}{l}5.7 \\
4.8\end{array}$ \\
\hline Glyptol ............... & $4.4 \times 10^{7}$ & 45000 & Bakelite No. G $3622 .$. & $3.3 \times 10^{8}$ & 1.5 \\
\hline Bakelite No. I $530 \mathrm{x} . .$. & $1.7 \times 10^{10}$ & 35000 & Bakelite No. G $3623 .$. & $1.3 \times 10^{9}$ & 1.4 \\
\hline Electrose No. 8........ & $4.2 \times 10^{9}$ & 380 & Bakelite No. G 3618 a.. & $1.1 \times 10^{8}$ & 1.2 \\
\hline Hard rubber *......... & $6.4 \times 10^{6}$ & 280 & Gummon............... & $1.9 \times 10^{8}$ & 1.2 \\
\hline Bakelite No. L 530y. . & $3.8 \times 10^{9}$ & 260 & G. E. No. 55 R... & $1.1 \times 10^{10}$ & 1 \\
\hline Insulate No. $2 \ldots \ldots \ldots$ & $1.6 \times 10^{0}$ & 190 & Moulded mica ..... & $2.5 \times 10^{9}$ & 1 \\
\hline Italian marble ......... & $1.7 \times 10^{8}$ & 36 & Brown glass.... & $7.1 \times 10^{7}$ & 0.8 \\
\hline Bakelite No. G 3618 b. . & $3.5 \times 10^{8}$ & 27 & Clear glass .......... & $2.9 \times 10^{8}$ & 0.8 \\
\hline Amberite........... & $1.2 \times 10^{10}$ & 12 & Murdock No. 200... & $1.1 \times 10^{9}$ & 0.2 \\
\hline
\end{tabular}

* The "hard rubber covered with bakelite" was cut from the same sample as the "hard rubber."

The results may be divided into two classes-those which show a decrease in surface resistivity and those in which there is no change. The table is arranged so that not only are these classes shown, but also the materials in the first class are arranged in the order of their relative change. While these results can not be taken as indicating that if the substances were exposed to sunlight for a sufficiently long time, the change in surface resistance would be the same relatively as that given in the table, yet the results upon the few substances which have been examined point in that direction. 


\section{NATURE OF SURFACE LEAKAGE}

We have assumed that surface leakage is due to a film of moisture or other conducting material on the surface of the insulator. If this is the case, it should be possible to find some connection between the thickness of the film, the conductivity of material of which it is composed, and the surface resistivity. In the case of quartz and various kinds of glass, the thickness of the water film condensed upon the surface when a sample is placed in a humid atmosphere has been determined by weighing. It should, therefore, be possible to determine the conductivity of the water in the film and see if this is a value such as might be expected.

Ihmori ${ }^{12}$ found that the thickness of the film on cleaned quartz at about 90 per cent humidity is from 0.003 to 0.006 micron ( 3 to $6 \times 10^{-6} \mathrm{~mm}$ ). With uncleaned specimens he found the thickness to be from 0.014 to 0.062 micron. Briggs ${ }^{13}$ found at 85 per cent a thickness of 0.0045 micron of water on a quartz surface and of 0.027 micron at 99 per cent humidity. If the value of the thickness is taken as 0.06 micron (the highest measured value) and the surface resistivity as $10^{-8} \mathrm{ohms}$ (the lowest value measured), the conductivity of the water is $0.0017 \mathrm{mho}$ per $\mathrm{cm}$. Since quartz is practically insoluable, the conductivity is largely due to soluble salts on the surface.

If this conductivity is due to the presence of sodium chloride, there must be present on each square centimeter of surface $6 \times 10^{-9}$ gram of the salt. It is evident that cleaning must be done with great care to exclude such minute quantities of impurities.

Besides soluble salts on the surface, there may be gases condensed from the air which will affect the conductivity. Those most to be expected are ammonia and carbon dioxide. Under the conditions of this experimental work, the ammonia would be rapidly absorbed by the sulphuric acid used to control the humidity. To insure the absorption of the carbon dioxide, a solution of potassium hydroxide was made, the vapor pressure of which was such as to give a humidity of 95 per cent in the surrounding air. This was used in conjunction with a sulphuric acid solution 
having the same vapor pressure. The results obtained showed that even in the case of cleaned quartz the carbon dioxide absorbed from the air has very little effect on the resistivity.

In the case of the cleaned quartz, the surface resistivity is about $\mathrm{IO}^{12}$ ohms at 90 per cent humidity, and; from the work quoted, the thickness of the water layer is about 0.005 micron. The conductivity of the water is then $2 \times 10^{-6}$ mho per $\mathrm{cm}$. This is of the same order of magnitude as the conductivity of distilled water.

In the case of glass, it is well known that certain salts from the glass dissolve in water. Hence, cleaning glass will not be expected to produce the same effect as in the case of quartz. Experiment has shown this to be the case. Soft glasses are very little affected by cleaning, but the more insoluble glasses show considerable change after thorough cleaning, but this is in no case as pronounced as in the case of quartz.

Parks ${ }^{14}$ finds that the thickness of the water film on glass is about o.I micron. The lowest measured value of the surface resistivity of glass recorded in this paper is $2 \times 10^{7}$ ohms. This gives a value of the conductivity of the water $5 \times 10^{-3}$ mho per $\mathrm{cm}$, or a volume resistivity of $200 \mathrm{ohm}-\mathrm{cm}$. This can be explained by the solubility of the glass in water.

Amber is a very insoluble substance, and the effect of cleaning is quite as marked as in the case of quartz. However, no data on the thickness of the surface film has come to the notice of the author.

Attention has been called to the fact that in the case of hard rubber at very low humidities the presence of salts on the surface does not affect the surface leakage. It appears, therefore, that the surface leakage at higher humidities is due to a film of water in which the salts are dissolved.

In the case of the waxy materials, the angle of contact between water and the material is greater than $90^{\circ}$. If water is condensed upon the surface of one of these materials it tends to draw into drops, instead of spreading over the surface. Hence, it would be expected that the leakage resistance of waxy materials would be 
very little affected by a change in humidity. That this is the case has already been shown. From measurements of the resistance, the presence of a surface film on these materials can not be detected.

From the cases which have been cited, it appears that when placed in an atmosphere having high humidity the decrease in the surface resistance of insulators is due to the condensation of moisture on the surface. Any condition which will affect either the amount of moisture on the surface or its conductivity will affect the surface leakage. Hygroscopic salts will increase the thickness of the water film, and any soluble salt will increase its conductivity. Hence the presence of inorganic salts on the surface of an insulator produces a decrease in the surface resistivity. Since the quantity of water in the surface film is very small, the amount of salt required to produce very large changes in the surface resistivity is exceedingly minute.

Besides water films, thin films of oil are often present on the surface of insulators. The volume resistivity of oil is much higher than water. The values found in this laboratory range from $1 \mathrm{O}^{11}$ to $10^{15} \mathrm{ohm}$-centimeters for good mineral oil, and from $10^{8}$ to IO ${ }^{12}$ for animal and vegetable oils.

If we assume that the thickness of the oil film is o.I micron and that the resistivity of the oil is $10^{11}$ ohm-centimeters, the surface resistivity would be $10^{16} \mathrm{ohms}$. Since very few of the curves go above this value, it seems probable that the surface resistivity is generally limited by the resistance of a film of oil on the surface of the insulator. The only exceptions are the waxy materials.

\section{METHODS OF COMPUTING SURFACE RESISTIVITY}

The surface resistance must always be computed from measurements of the leakage resistance and volume resistivity. In the great majority of cases the current which flows through the solid is such a small part of the total that the surface resistance does not differ from the leakage resistance by as much as the error of measurement. However, at very low humidities this may not be the case. The resistance which the solid insulator offers to the flow of current can be computed for certain forms of electrodes, and in these cases the surface resistance can be obtained. One 
case which can be solved is that of two narrow strips of conductors placed upon the surface of an insulator. ${ }^{15}$

If two strips of width $a \mathrm{~cm}$ and of infinite length are so pressed upon the surface of an insulator of infinite surface and thickness that the distance between their inner edges is $b \mathrm{~cm}$, the resistance, $R$, per unit length between these strips is-

$$
R=\frac{2 K}{K^{\prime}} \rho
$$

where $K$ and $K^{\prime}$ are the complete ellpitic integrals ${ }^{16}$ of the first kind to the moduli $k$ and $k^{\prime}$ respectively, where $k=\frac{b}{b+2 a}$ and $k^{\prime}=$ $\sqrt{I-k^{2}}$.

From this formula the first four values in Table 6 have been computed. In three respects the above differs from the form which we have employed. Strips of infinite length have not been used, but it has already been noted that the correction on this account is negligible. The insulator is of finite breadth as well as length. But as very little of the current will flow in the region outside the strips, the correction on this account is negligible. The insulator is of finite thickness, and it is on this account that the only appreciable correction will enter.

Another case which can be solved is that of two infinitely wide strips upon an insulator of infinite thickness ${ }^{17}$ except at a point midway between the conductors.

The shape will be seen from Fig. 29. If two conductors, each infinitely wide and long, are placed $b \mathrm{~cm}$ apart on an insulator of infinite thickness, but having a slit to within $c \mathrm{~cm}$ of the top surface at a point midway between the conductors $R=\frac{2 K^{\prime}}{K}$ where in this case $k=\frac{c}{4 b^{2}+c^{2}}$ and therefore $k^{\prime}=\frac{2 b}{4 b^{2}+c^{2}}$.

Values for different thicknesses calculated by the two formulas are given in Table 6.

\footnotetext{
${ }_{15}$ The corresponding problem in electrostatics was solved by J. J. Thomson. (See Recent Researches in Electricity and Magnetism, p. 238.) It is only necessary to interpret the result given by Thomson in terms of resistance instead of capacity.

${ }_{16}$ Tables of the numerical values of these integrals can be found in Legendrés Traitè des Functions Elliptiques, volume 2, and in this Bulletin, 8, p. 202, Reprint 169. The value can, however, be computed with much greater precision than is demanded by this work from the relation $\frac{K}{K^{\prime}}=\left(\frac{1+k^{\prime}}{I+k}\right)^{2}$

17 The corresponding case in electrostatics is given by J. J. Thomson. Loc. Cit., p. 243.
} 
TABLE 6

Table showing the Resistance between two Strips on the Surface of an Insulator if all of the Current flows through the Body of the Insulator

\begin{tabular}{c|c|c|c}
\hline Width of strip (a) & $\begin{array}{c}\text { Distance between strips } \\
\text { (b) }\end{array}$ & $\begin{array}{c}\text { Thickness of insulator } \\
\text { at center (c) }\end{array}$ & Resistance \\
\cline { 1 - 2 }$c m$ & $c m$ & $c m$ & $\rho=$ volume resistivity \\
0.01 & 1 & $\infty$ & $3.9 \rho$ \\
0.1 & 1 & $\infty$ & $2.4 \rho$ \\
1.0 & 1 & $\infty$ & $1.3 \rho$ \\
10.0 & 1 & $\infty$ & $0.7 \rho$ \\
$\infty$ & 1 & 1.0 & $2.7 \rho$ \\
$\infty$ & 1 & 0.5 & $3.6 \rho$ \\
\hline
\end{tabular}

While at first this seems to be very different from the case we are considering, yet a consideration of the lines of flow will show that the removal of the portion outside the dotted lines in Fig. 29 will not greatly change the resistance.

From a consideration of these values we have concluded that, for the samples which have been used in this investigation, the resistance of the body of the insulator is three times the volume resistivity of the material. Some experimental work where the surface

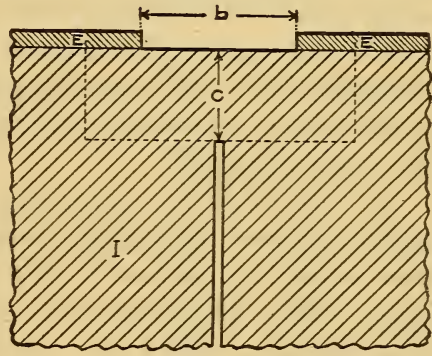
film was reduced to a minimum Fig. 29.-Diagram showing an insulator of gave 3.3. Hence, for the order of accuracy which can be attained sueh form that the resistance between the eleetrodes eau be computed in this work, it is sufficient to say that the resistance of the body of the insulator is three times the volume resistivity of the material.

Since the leakage resistance per unit length, $r$, consists of the surface resistance and volume resistance in parallel, it follows that the surface resistivity $\sigma$ is given by the equation

$$
\sigma=\frac{3 r \rho}{3 \rho-r}
$$

where $r$ is the leakage resistance per unit length. 
If $3 \rho$ is large relative to $r$, then $\sigma=r$ and $\sigma$ is determined with the same accuracy as $r$. But when $r$ approaches in value $3 \rho, \sigma$ becomes very large and errors in either $r$ or $\rho$ will introduce much larger errors in $\sigma$. It is therefore at the low humidities where $\sigma$ is large that the values are most inaccurate. Fortunately, it is in this region that precise values are of the least importance in practical work.

When this work was in progress and the curves constructed, the necessity for applying the correction outlined above was not appreciated. From the results which have already been given showing the factors which affect both the volume resistivity and the surface resistivity, it will be seen that it is possible to make an accurate determination of the surface resistivity only when the leakage resistivity and volume resistivity are measured at the same time. As it is only at low humidities that the correction is appreciable and as at these humidities the surface leakage is seldom of importance, the curves showing the change of surface resistivity with humidity have not been changed. However, in order to show the magnitude of the correction in the most unfavorable cases, Table 7 has been prepared.

In this table are given the measured values of the volume resistivity and the leakage resistivity at low humidity. The surface resistivity at low humidity computed from these values is given in the third column. Those in which $r$ is larger than $3 \rho$ give negative values of $\sigma$, while those in which $r$ equals $3 \rho$ give infinite values of $\sigma$. Such values of $\sigma$ can only be accounted for by errors in the value of either $r$ or $\rho$. The values of $\rho$ are a weighted mean of several different samples measured at different times. The values of $r$ are from a curve for one sample which was chosen as representative of several samples measured. Hence, it is not surprising that the values of $r$ and $\rho$ can not in all cases be used in computing $\sigma$. 


\section{TABLE 7}

Table Giving Values of the Volume Resistivity, the Leakage Resistivity, and the Surface Resistivity at Low Humidities

[Humidities 20 per cent or less. $\rho=$ Volume resistivity; $\tau=$ Leakage resistivity; $\sigma=$ Surface resistivity]

\begin{tabular}{|c|c|c|c|}
\hline Sample & $\rho$ & $r$ & $\sigma$ \\
\hline Galalith, white ........ & $1 \times 10^{10}$ & $7 \times 10^{10}$ & * \\
\hline Yellow condensite.... & $1 \times 10^{11}$ & $6 \times 10^{11}$ & * \\
\hline Black condensite........... & $4 \times 10^{10}$ & $20 \times 10^{10}$ & * \\
\hline White celluloid............. & $2 \times 10^{10}$ & $10 \times 10^{10}$ & * \\
\hline Bakelite No. $1 . \ldots \ldots \ldots$ & $2 \times 10^{111}$ & $10 \times 10^{11}$ & * \\
\hline Bakelite No. $190 \ldots . . . .$. & $1 \times 10^{11}$ & $5 \times 10^{11}$ & * \\
\hline Galalith, black........... & $2 \times 10^{1010}$ & $10 \times 10^{10}$ & * \\
\hline Plate glass............ & $2 \times 10^{13}$ & $6 \times 10^{18}$ & * \\
\hline 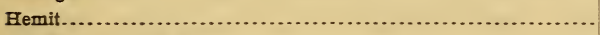 & $1 \times 10^{10}$ & $3 \times 10^{10} 0$ & * \\
\hline Bakelite 5200 R. G. R...... & $4 \times 10^{11}$ & $10 \times 10^{11}$ & $60 \times 10^{11}$ \\
\hline Bakelite 5199 R. G. R. B.... & $5 \times 10^{12}$ & $10 \times 10^{12}$ & $30 \times 10^{13}$ \\
\hline Tetrachlornaphthalene...... & $5 \times 10^{13}$ & $10 \times 10^{13}$ & $30 \times 10^{13}$ \\
\hline Bakelite No. $150 \ldots \ldots \ldots .$. & $4 \times 10^{12}$ & $8 \times 10^{12}$ & $24 \times 10^{29}$ \\
\hline Bakelite No. I 558 . . . . . . . . . & $2 \times 10^{16}$ & $3 \times 10^{16}$ & $9 \times 10^{16}$ \\
\hline Gummon..................... & $3 \times 10^{12}$ & $4 \times 10^{-3}$ & $7 \times 10^{28}$ \\
\hline 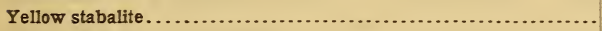 & $4 \times 10^{13}$ & $5 \times 10^{13}$ & $9 \times 10^{18}$ \\
\hline J-P Bakelite ..................... & $2 \times 10^{10}$ & $2 \times 10^{10}$ & $3 \times 10^{10}$ \\
\hline Dielectrite.................... & $5 \times 10^{12}$ & $6 \times 10^{12}$ & $10 \times 10^{12}$ \\
\hline Tegit....................... & $2 \times 10^{12}$ & $2 \times 10^{12}$ & $3 \times 10^{12}$ \\
\hline Bakelite micarta ............... & $5 \times 10^{10}$ & $5 \times 10^{10}$ & $8 \times 10^{10}$ \\
\hline Moulded mica............... & $10 \times 10^{14}$ & $7 \times 10^{14}$ & $9 \times 10^{24}$ \\
\hline G. E. No. 55A ................. & $10 \times 10^{14}$ & $5 \times 10^{14}$ & $6 \times 10^{14}$ \\
\hline Redmonite No. $157,4 \ldots \ldots \ldots$. & $2 \times 10^{14}$ & $1 \times 10^{14}$ & $1 \times 10^{24}$ \\
\hline G. E. No. $40 \ldots \ldots \ldots \ldots$ & $10 \times 10^{14}$ & $3 \times 10^{14}$ & $3 \times 10^{14}$ \\
\hline 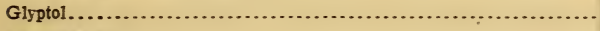 & $10 \times 10^{15}$ & $2 \times 10^{15}$ & $2 \times 10^{15}$ \\
\hline Electrose No. $8 \ldots \ldots \ldots \ldots$. & $20 \times 10^{15}$ & $4 \times 10^{15}$ & $4 \times 10^{16}$ \\
\hline Yellow electrose............ & $5 \times 10^{15}$ & $1 \times 10^{15}$ & $1 \times 10^{15}$ \\
\hline Murdock No. $100, \ldots . . . .$. & $30 \times 10^{14}$ & $5 \times 10^{14}$ & $5 \times 10^{14}$ \\
\hline Insulate No. $2 \ldots \ldots \ldots$ & $80 \times 10^{14}$ & $4 \times 10^{14}$ & $4 \times 10^{14}$ \\
\hline Black electrose..... & $100 \times 10^{12}$ & $5 \times 10^{12}$ & $5 \times 10^{13}$ \\
\hline Amberite................ & $50 \times 10^{15}$ & $2 \times 10^{15}$ & $2 \times 10^{15}$ \\
\hline G. E. No. 55R ...... & $400 \times 10^{14}$ & $7 \times 10^{14}$ & $7 \times 10^{14}$ \\
\hline
\end{tabular}

*Due to error in the determination of either $\rho$ or $\tau$, or both, the value of $\sigma$ cannot be computed. When $\tau$ is of nearly the same value as $3 \rho$, small errors in either $r$ or $\rho$ will produce large errors in $\sigma$.

All of the materials in which the difference between $r$ and $\sigma$ is large have volume resistivities less than $\mathrm{IO}^{14}$ and the majority less than $\mathrm{IO}^{12}$. Where the volume resistivity is as low as this, a knowledge of the surface resistivity will seldom be of importance. For humidities greater than about 25 per cent the surface resistance is the same as the leakage resistance except in the case of the waxy 
materials. It is quite probable that for these materials a surface film does not exist, so that the surface resistivity is infinite.

In the preceding discussion it has been assumed that the air which is above the solid dielectric is a perfect insulator. This is true except in so far as the air is ionized. Hence, the current that flows through the air depends only on the number of ions present provided the potential gradient is sufficiently high to cause them to travel toward the electrodes. When the potential is applied, the ions which are already present are immediately carried to the electrodes, so that the continuous current depends on the rate of production of ions. The natural rate of ionization of the air is about 6 ions per second per cubic centimeter of air. The charges carried by these ions are approximately $\mathrm{IO}^{-18}$ coulomb. If we assume that the ions from $10 \mathrm{~cm}^{3}$ of air will be drawn to unit length of the plates, the total current due to air conduction is only $\mathrm{IO}^{-17}$ ampere, which is quite negligible in comparison to the surface leakage of most materials. However, in case currents of air are passing over the dielectric the electric current through the air may be much larger, since the number of ions normally found in $\mathrm{a} \mathrm{cm}^{3}$ of air varies from 1000 to 2000 . If the air over the specimen is completely changed ro times per second, the current will become $3 \times 10^{-14}$ ampere, an amount which becomes of the same magnitude as the surface current for the best specimens. Also the presence of any ionizing agent such as radium, Roentgen rays or ultra-violet light will increase the ionization and hence the current.

\section{SUMMARY}

I. Methods of measuring very high resistances are discussed, and diagrams given showing how they may be applied to the measurement of volume resistivity and surface resistivity.

2. The volume resistivities of more than 60 materials are tabulated. The effect of the humidity of the surrounding air, of the temperature of the specimen, and of the magnitude and length of application of the impressed voltage is discussed.

3. The surface resistivity is shown to be due to a surface film, usually of water or oil, on the insulator. This is generally the important factor in determining the leakage between two conduc- 
tors insulated by a solid dielectric. However, for insulators having a volume resistivity less than $\mathrm{rO}^{14} \mathrm{ohm}$-centimeters placed in an atmosphere having an humidity less than 25 per cent, the greater part of the current may flow through the body of insulator.

4. The surface resistivity of most materials changes through wide limits when the humidity of the surrounding air is varied. It is often a million times as great at low humidity as at high humidity. About 75 curves are given showing the change of surface resistivity with humidity for various materials. The effects of temperature and of exposure to light are also treated.

In conclusion, I wish to recognize valuable assistance from my coworkers in the Bureau of Standards. I would especially mention Mr. Maxwell James who has made many of the measurements upon volume resistivity. I wish also to thank those firms who cooperated by furnishing materials.

WASHINGTON, June 8, I9I4. 


\section{APPENDIX}

\section{TABLE 8}

Volume Resistivity of Solid Dielectrics (materials listed alphabetically)

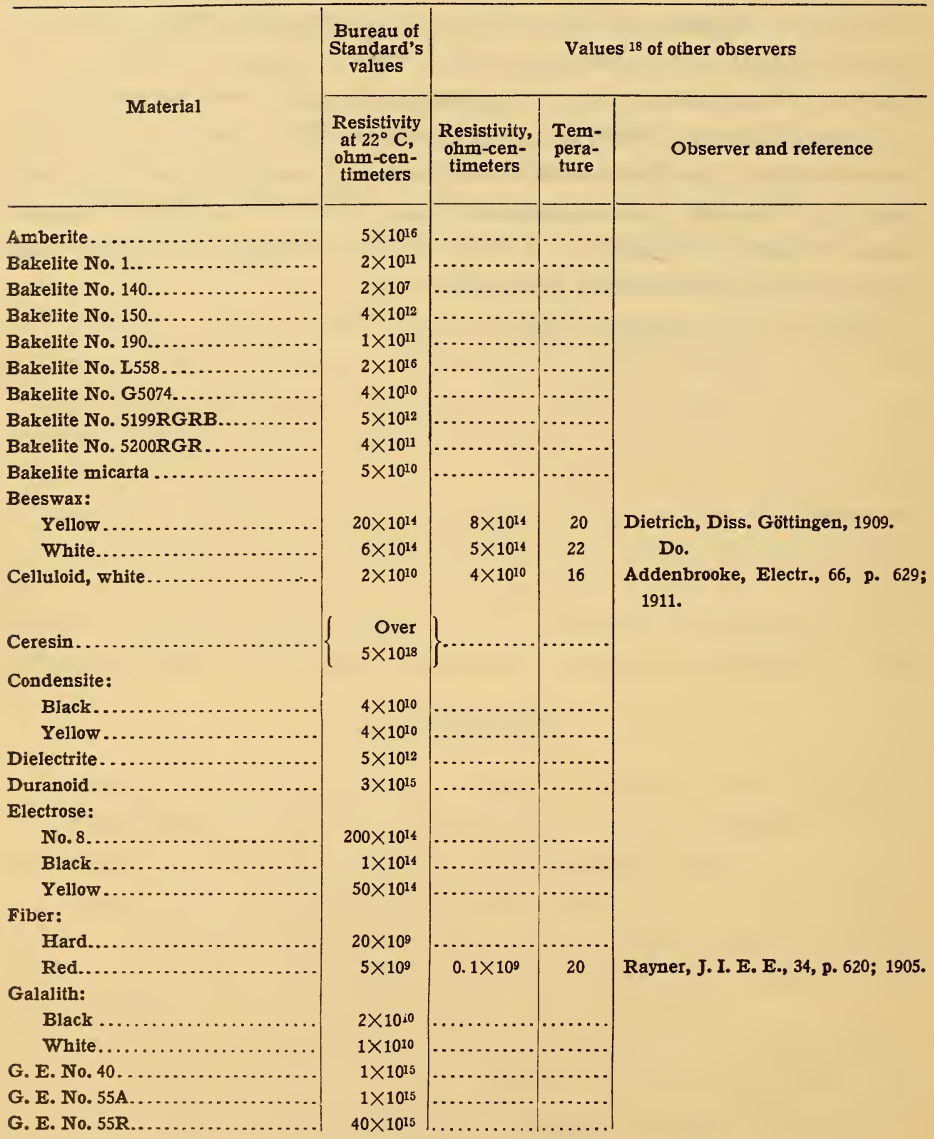

18 When necessary the values have been reduced to the units given in the table. 418 
Volume Resistivity of Solid Dielectrics (materials listed alphabetically)-Continued

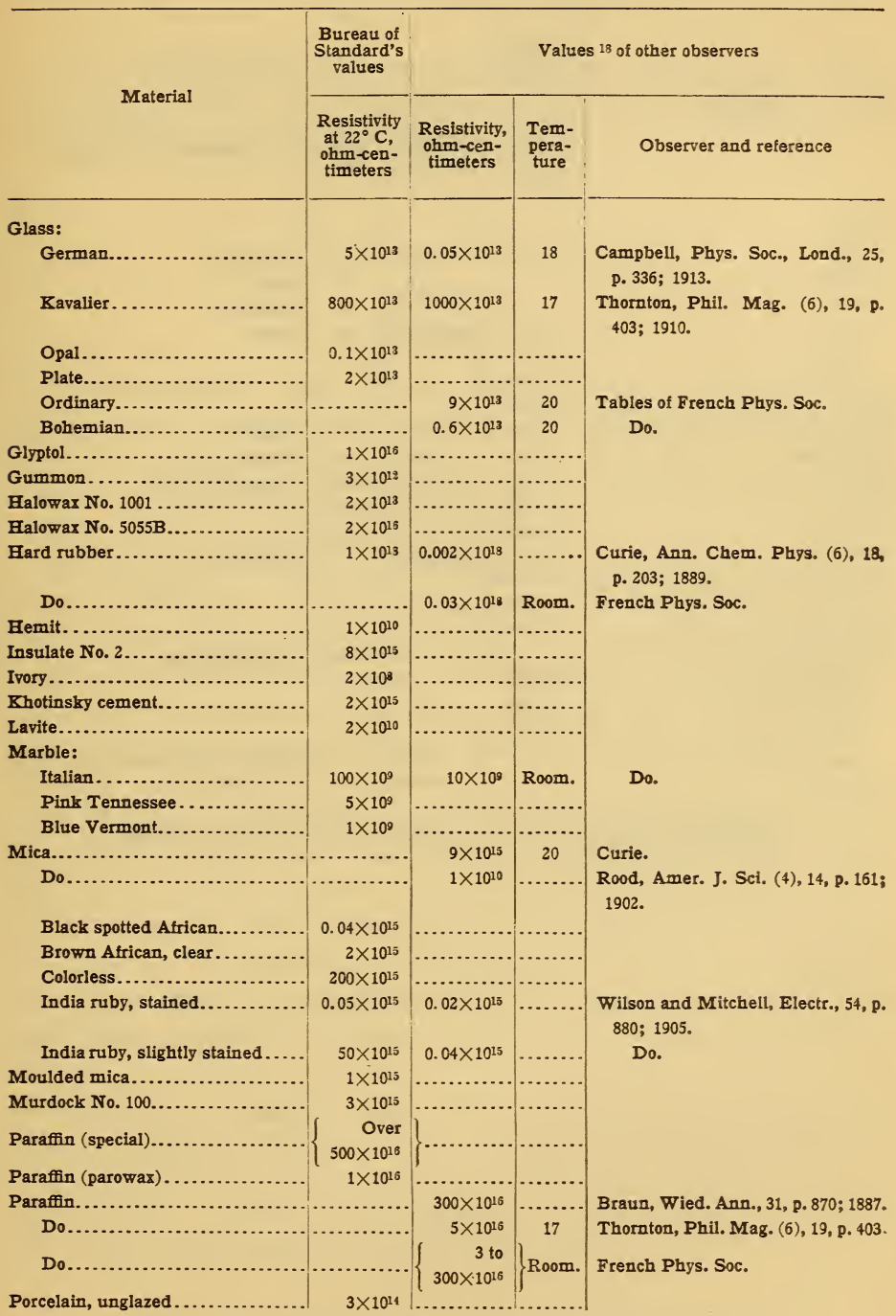

18 When necessary the values have been reduced to the units given in the table. 
Volume Resistivity of Solid Dielectrics (materials listed alphabetically)—Continued

\begin{tabular}{|c|c|c|c|c|}
\hline \multirow{2}{*}{ Material } & \multirow{2}{*}{ 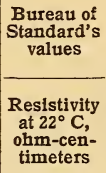 } & \multicolumn{3}{|c|}{ Values 18 of other observers } \\
\hline & & $\begin{array}{l}\text { Resistivity, } \\
\text { ohm-cen- } \\
\text { timeters }\end{array}$ & $\begin{array}{l}\text { Tem- } \\
\text { pera- } \\
\text { ture }\end{array}$ & Observer and reference \\
\hline \multicolumn{5}{|l|}{ Quartz: } \\
\hline$\|$ to aris.. & ........ & $2 \times 10^{14}$ & 17 & Thornton. \\
\hline Do.................... & $\ldots \ldots \ldots \ldots$ & $1 \times 10^{14}$ & 20 & Curie. \\
\hline$\perp$ to axis............. & $\ldots \ldots \ldots \ldots$ & $200 \times 10^{14}$ & 17 & Thornton. \\
\hline 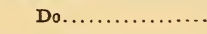 & (n.......... & $300 \times 10^{14}$ & 20 & Curie. \\
\hline Fused.. & Over & & & \\
\hline Redmonite, $157-4 \ldots$ & $2 \times 10^{14}$ & & & \\
\hline Rosin.................. & $5 \times 10^{16}$ & $0.7 \times 10^{16}$ & 17 & Thornton. \\
\hline Sealing wax......... & $8 \times 10^{15}$ & $1 \times 10^{15}$ & 19 & Dietrich. \\
\hline Shellac................ & $1 \times 10^{16}$ & $0.9 \times 10^{16}$ & Room. & French Phys. Soc. \\
\hline Slate................. & $1 \times 10^{8}$ & $2 \times 10^{8}$ & Room. & Do. \\
\hline Stabalite.............. & $3 \times 10^{13}$ & (.............. & ......... & \\
\hline Sulphur............... & $1 \times 10^{17}$ & $0.08 \times 10^{17}$ & 17 & Thornton. \\
\hline Tegit................. & $2 \times 10^{12}$ & & & \\
\hline Tetrachlornaphthalene. & $5 \times 10^{13}$ & ..... & & \\
\hline Vulcabeston $19 \ldots \ldots$. & $2 \times 10^{10}$ & ......... & & \\
\hline Wood, paraffined... & (n.......... & $5 \times 10^{10}$ & Room. & French Phys. Soc. \\
\hline Mahogany........ & $4000 \times 10^{10}$ & & & • \\
\hline Maple........... & $3 \times 10^{10}$ & & & \\
\hline Poplar............ & $50 \times 10^{10}$ & ... & & $x^{-}$ \\
\hline Walnut & & $\begin{array}{l}0.09 \text { to } \\
1 \times 10^{10}\end{array}$ & & $\left\{\begin{array}{c}\text { E. Muller, Electrotech. Zs., 13, p. } \\
72 ; 1892 .\end{array}\right.$ \\
\hline
\end{tabular}

${ }^{18}$ When necessary the values have been reduced to the units given in the table. 19 Vulcabeston should read "J-P Bakelite." 